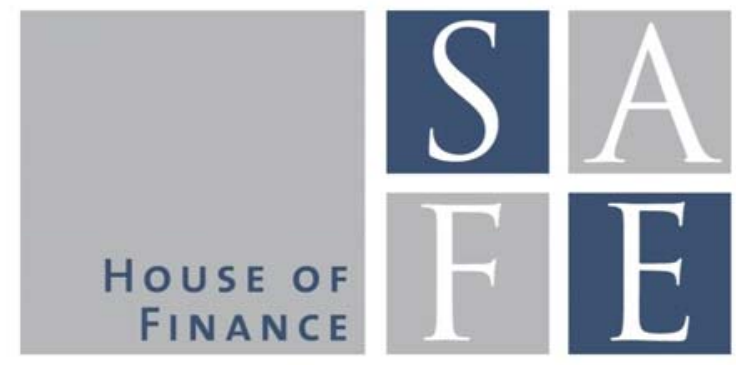

WORKING PAPER SERIES

Giuliano Curatola

\title{
Preference Evolution and the Dynamics of Capital Markets
}

SAFE Working Paper No. 128

SAFE I Sustainable Architecture for Finance in Europe

A cooperation of the Center for Financial Studies and Goethe University Frankfurt 


\section{Non-Technical Summary}

Traditional economic literature assumes that individuals' preferences are exogenously given and remain unchanged over time. However, as our everyday life suggests, preferences and tastes may change for a number of reasons: circumstantial changes, age-related issues, social interaction, acquisition of new information or sensitivity to fashion trends. As a result the choice among different consumption goods depends on the evolution of consumers' taste over time. In this paper, I assume that consumers' preferences evolve over time as a product of social interaction among individuals. Social interaction occurs because investors are sensitive to fashion cycles of consumption goods that, in turn, depend on individuals' optimal consumption choices. The dynamics of preference evolution described above is incorporated into an otherwise standard Lucas-type exchange economy and I characterize the implications of time variation in preferences for investors' trading strategy, asset price and return dynamics. The economy is populated with two types of agents, conformist and anti-conformist. The preferences of conformist investors evolve in favor of fashionable consumption goods, while the preferences of anti-conformist investors evolve in favor of out-of-fashion consumption goods.

The interaction of preference evolution and standard market forces of pure-exchange economies generates the following dynamics of trading strategies and stock returns. First, the portfolio of conformist investors is biased toward companies (or sectors) that produce fashionable goods while the portfolio of anti-conformist investors is biased toward companies (or sectors) that produce out-of-fashion goods. This implies that investors with time-varying preferences may end up with a portfolio of socially desirable but poorly performing stocks. Second, preference evolution implies that stock return and asset prices are both time-varying, therefore assets with high price-dividend ratio may have high expected returns or low expected returns depending on cash-flow characteristics and the percentage of conformist/anticonformist investors in the economy. Stock market volatility is also time-varying and depends on the perception of consumption risk induced by conformist and anti-conformist behavior. Conformist investors find it difficult to imitate other investors when one of the consumption goods becomes extremely popular and all investors desire to buy that good. Therefore, when the majority of investors in the economy are conformist, the return volatility is high when a consumption good becomes more popular relatively to the others. Differently, anti-conformist investors find it difficult to differentiate themselves from others when the consumption goods in the economy have similar popularity. Therefore, when the majority of investors are anticonformist, the return volatility is high when the consumption goods are equally popular among investors.

In summary, this paper introduces a novel reason (i.e. preference evolution) for time variation in asset prices that offers a possible explanation for several stylized facts of financial markets. 


\title{
Preference Evolution and the Dynamics of Capital Markets
}

\author{
Giuliano Curatola*
}

Goethe Universität Frankfurt

March 13, 2016

\begin{abstract}
This paper introduces endogenous preference evolution into a Lucas-type economy and explores its consequences for investors' trading strategy and the dynamics of asset prices. In equilibrium, investors herd and hold the same portfolio of risky assets which is biased toward stocks of sectors that produce a socially preferred good. Price-dividend ratios, expected returns and return volatility are all time varying. In this way, preference evolution helps rationalize the observed under-performance and local biases of investors' portfolios and many empirical regularities of stock returns such a time variation, the value-growth effect and stochastic volatility.
\end{abstract}

Keywords: Asset pricing, general equilibrium, heterogeneous investors, interdependent preferences, portfolio choice.

JEL Classification Numbers: D51; D91; E20; G12.

*I would like to thank Julien Hugonnier for his continual support and advice throughout this work. I also thank Nicole Branger, Andrea Buraschi, Enrico De Giorgi, Jerôme Detemple, Pierre Collin-Dufresne, Diego Garcia, Alessandro Gioffré, Martin Herdegen, Yigitcan Karabulut, Leonid Kogan, Matti Keloharju, Holger Kraft, Marco Pagano, Roberto Marfé, Claudia Ravanelli, Jacob Sagi, Christian Schlag and David Solomon for stimulating discussions and suggestions. All the participants to the XXIV Rome Conference on Money Banking and Finance, the VI workshop on Strategic Interaction and General Equilibrim: theory and applications, the XXI Finance Forum and the 2012 Gerzensee doctoral workshop are gratefully acknowledged. Ilya Dergunov provided excellent research assistance. All errors are my own. A previous version of this paper circulated under the title Consumption-based asset pricing with herd behavior. I gratefully acknowledge financial support from the Center of Excellence SAFE, funded by the State of Hessen initiative for research LOEWE. e-mail: curatola@safe.uni-frankfurt.de 


\section{Introduction}

Traditional economic analysis stems from the assumption that individuals' preferences are exogenously given and remain unchanged over time. However, preferences and tastes may change for a number of reasons, pertaining to exogenous factors, such as circumstantial changes and age-related issues, or endogenous factors, such as social interaction, acquisition of new information or sensitivity to fashion trends. In this paper, I consider the case of endogenous preference evolution that occurs as a product of social interaction among individuals. I assume that social interaction occurs because investors are sensitive to fashion cycles of consumption goods that, in turn, depend on individuals' optimal consumption choices. As a result, individual preferences in my model are interdependent and evolve over time in response to endogenous changes in the observed popularity of consumption goods. The idea that individual preference change over time in reaction to other people's consumption choice is already well established in the economic literature (Pollak (1979) and Bell (2002)), but its implications for the dynamics of the financial market have never been investigated.

I incorporate preference evolution into a Lucas-type exchange economy and characterize the implications of time variation in preferences for investors' trading strategy, asset price and return dynamics. There are two categories of investors, conformist and anti-conformist, both equipped with separable utility over two consumption goods and a time-varying preference attached to each good. The preferences of conformist investors evolve in favor of fashionable consumption goods, while the preferences of anti-conformist investors evolve in favor of out-of-fashion consumption goods. The interaction of preference evolution and standard market forces of pure-exchange economies generates interesting equilibrium dynamics of trading strategies and stock returns. First, fashion waves in the demand of consumption goods are transmitted to the financial market: conformist investors show a bias toward companies (or sectors) that produce fashionable goods while anti-conformist investors show a bias toward companies (or sectors) that produce out-offashion goods. This implies that financial wealth fluctuates across sectors irrespective of expected returns and Sharpe ratios. As a result, there are regions of the state space in 
which expanding sectors have the lowest expected returns/Sharpe ratios, which is in line with the recent empirical evidence of Bansal et al. (2005).

Concerning aggregate quantities, preference evolution implies that price-dividend ratios and expected stock returns vary non-monotonically with the popularity of consumption goods. Thus, assets with high price-dividend ratio may have high expected returns (i.e. the "growth" effect) or low expected returns (i.e. the "value" effect) depending on cash-flow characteristics and the percentage of conformist/anti-conformist investors in the economy. Stock returns and return volatility fluctuate over time due to the time-varying perception of consumption risk induced by conformist and anti-conformist behavior. Conformist investors dislike states of the world where it is relatively difficult to imitate the consumption basket of other investors. This happens when one of the two consumption good becomes extremely popular and all conformist investors desire to buy that good. Therefore, when the majority of investors in the economy are conformist, the equity premium and the return volatility are high when one of the two goods becomes more popular relatively to the other. Vice-versa, anti-conformist investors dislike states of the world in which it is relatively difficult to make non-conformist choices which allow for differentiation from others. This happens when the two goods have similar popularity. Therefore, when the majority of investors are anti-conformist, the equity premium and the return volatility are high when the two goods are equally popular among investors.

This paper is related to the recent literature on asset-pricing models with multiple risky assets. Cochrane et al. (2008) consider an economy with two stocks and log-preferences when dividends are driven by geometric Brownian motions. Martin (2013) studies the general case of $N \geq 2$ stocks and power utility. Branger et al. (2011) analyze an economy with two stocks, log-preferences and stochastic drift for one of the two stock. Chabakauri (2013) considers the case of two stocks, power utility and portfolio constraints. These papers are characterized by a single consumption good whose supply is determined by the sum of all dividend payments and, therefore, investors do not trade goods but only financial assets. Non-trivial implications follow by introducing trade in goods and preference evolution. Indeed, when preferences are time varying, the relative price of available goods 
depends not only on their supply, as customary in economies with multiple goods, but also on the aggregate preference for consumption goods. When the aggregate preferences evolve in favor of a given consumption good, that good becomes relatively more expensive. As a result, the investors in my economy face a trade-off between the desire to consume the preferred good and the price of that good. This trade-off produces non-trivial implications for the dynamics of the investors' consumption basket that are analyzed in this paper.

Introducing multiple goods into a Lucas-type economy poses a technical challenge. Cass and Pavlova (2004) show that in a pure-exchange economy with multiple consumption good and log utility, financial markets are incomplete even if there are as many sources of risk as risky assets. In this perspective, my paper offers a technical contribution and shows that when preferences evolve endogenously in response to changes in the popularity of consumption goods, financial markets are complete even if investors are equipped with $\log$ utility.

The rest of the article is structured as follows. Section 2 describes the primitives of the economy, the financial market and investors preferences. Section 3 presents the competitive equilibrium. The quantitative implications for stock prices and returns are analyzed in section 4 . Section 5 concludes.

\section{The Economy}

I consider a continuous-time pure-exchange economy in the spirit of Lucas (1978). The economy has an infinite horizon and the uncertainty is represented by a filtered probability space $\left(\Omega, \mathcal{F},\left\{\mathcal{F}_{t}\right\}, \mathbb{P}\right)$ on which is defined a two-dimensional Brownian motion $B=\left(B_{1}, B_{2}\right)$. All stochastic processes are assumed to be adapted to $\left\{\mathcal{F}_{t}\right\}$, the augmented filtration generated by $B$. All investors have the same beliefs about the state of the economy represented by the probability measure $\mathbb{P}$. 


\subsection{Consumption goods}

There are two perishable consumption goods, 1 and 2, each of them traded in a perfect spot market. $p_{t}$ denotes the 2-dimensional vector of relative goods prices. Good 1 serves as numeraire, thus, $p_{1, t}=1$ and $p_{2, t}$ represents the time- $t$ price of good 2 in terms of good 1. The two goods are produced according to a production technology (i.e. Lucas trees) whose ownership, represented by the stocks traded in the financial market, gives the investors the right to perceive a stream of dividend in the form of consumption goods. There are two independent trees, 1 and 2. Each tree $i, i \in\{1,2\}$, produces one stream of dividends paid in units of good $i$. The two dividend processes, represented by $\delta_{1}$ and $\delta_{2}$, follow an Itô process of the form

$$
d \delta_{i, t}=\delta_{i, t}\left(\nu_{i} d t+\phi_{i} d B_{i, t}\right)
$$

where $\delta_{i, 0}, \nu_{i}$ and $\phi_{i}$ are positive coefficients.

\section{$2.2 \quad$ Financial market}

Two stocks, 1 and 2, are traded on the market. Stock $i, i \in\{1,2\}$, represents the claim to dividend $i$ paid in unit of good $i$. The price of stock $i$ is denoted by $S_{i, t}$ and its dynamics satisfies

$$
d S_{i, t}+p_{i, t} \delta_{i, t} d t=S_{i, t}\left(\mu_{i, t} d t+\sigma_{i, 1, t} d B_{1, t}+\sigma_{i, 2, t} d B_{2, t}\right)
$$

where $\mu_{i}$ is the stock specific expected return and $\sigma_{i, j, t}$ represents the sensitivity of stock $i$ to shocks of dividend $j$, for $j=1,2$. Each stock is in positive supply of one unit. There is also a locally risk-free (in term of the numeraire consumption good) asset in zero net supply, whose price $S_{0, t}$ satisfies

$$
S_{0, t}=e^{\int_{0}^{t} r_{s} d s}
$$

for some risk-free rate of return $r_{t}$.

The asset price coefficients $\mu$ and $\sigma$, the risk-free rate $r$ and the relative price $p_{2}$ are 
to be determined endogenously in equilibrium.

\section{$2.3 \quad$ Preferences}

There is a continuum of investors with total mass equal to 1 and preferences for the two consumption goods $\left(c_{1}, c_{2}\right)$ represented by the functional

$$
U\left(c_{1}, c_{2}\right)=\alpha_{t} u\left(c_{1}\right)+\left(1-\alpha_{t}\right) u\left(c_{2}\right)
$$

where $u$ is a strictly concave and strictly increasing utility function and $\alpha_{t}$ determines the time-varying preference for the two consumption goods. Investors' preferences evolve over time in the spirit of Bell (2002) that is

$$
\alpha_{t}=\bar{\alpha}+k\left(s_{t}-\bar{s}\right)
$$

for some $\bar{s}$ and $\bar{\alpha}$ such that $0 \leq \alpha_{t} \leq 1$ for any $t$.

$s_{t}$, still to be formally defined, represents the time-varying popularity of good 1 . The rule of updating preferences defined in Eq. 5 implies that of investors' preferences evolve over time in response of changes in the popularity of available consumption goods ${ }^{1}$.

The parameter $k$ governs the direction of changes in preferences. Investors with $k=0$ are "fashion insensitive" in the sense that their preferences remain constant over time, irrespective of changes in the popularity of consumption goods. Investors with $k>$ 0 are "conformist" in the sense that their preferences evolve in favour of popular (or fashionable) goods. Finally, investors with $k<0$ are "anti-conformist" in the sense that their preferences evolve in favour of unpopular (or out-of-fashion goods). Consistent with this interpretation, I refer to the parameter $k$ as the investor's "fashion sensitivity". To capture different degree of fashion sensitivity I assume that fashion sensitivity is uniformly distributed over $[\underline{k}, \bar{k}]$ with $\underline{k} \leq 0$ and $\bar{k} \geq 0$.

\footnotetext{
${ }^{1}$ Clearly, other assumptions are possible here. For instance, one may assume that $\alpha$ is a nonlinear function of $s_{t}$ or that it depends on other equilibrium outcomes and not only on the popularity of available consumption goods. I choose $\alpha_{t}=\bar{\alpha}+k\left(s_{t}-\bar{s}\right)$ to be consistent with the existing micro-economic literature and discuss possible extensions in Section 5 .
} 
Changes in popularity of consumption goods may lead to a preference bias toward one of the two consumption goods. For instance, the preferences of conformist investors (i.e., those with $k>0$ ) are biased toward good $1(2)$ if $\alpha_{t}>(<) 1-\alpha_{t}$. The occurrence of a bias is governed by the parameter $\bar{s}$. More precisely,

$$
\begin{aligned}
\alpha_{t} & >1-\alpha_{t} \Leftrightarrow \\
s_{t} & >\bar{s}+\frac{0.5-\bar{\alpha}}{k} .
\end{aligned}
$$

In other words, the larger is $\bar{s}$, the larger has to be the popularity of good 1 to induce a conformist investor to prefer good 1 more than good 2. This captures the idea that the investor may have some personal arguments against good 1 which make him/her more "cautious" about increasing his/her preference for good 1. Similar computations show that $\bar{s}$ has the opposite effect on the preferences of anti conformist investors: the larger is $\bar{s}$, the lower has to be the popularity of good 1 to induce anti-conformist investors to prefer good 1 more than good 2 .

Once the distribution of the fashion sensitivity has been chosen, it is possible to formally define the popularity ratio $s_{t}$. I follow Bell (2002) and define $s_{t}$ as the average share of good 1 in the investors' total consumption basket. Formally,

$$
s_{t} \equiv \frac{1}{\Delta k} \int_{\underline{k}}^{\bar{k}}\left(\frac{c_{1 t}(k)}{c_{1 t}(k)+c_{2 t}(k)}\right) d k
$$

where $c_{i t}(k)$ represents the time- $t$ consumption of good $i$ of an agent with fashion sensitivity $k$ and $\Delta k \equiv \bar{k}-\underline{k}$ defines the length of the interval $[\underline{k}, \bar{k}]^{2} . s_{t}$ tracks the evolution of preferences over time and therefore is a natural state variable in the economy with preference evolution. From now on, I refer to $s_{t}$ as the "popularity ratio". Note that, in order for the popularity ratio to be well defined $c_{1}$ and $c_{2}$ must be similar goods and

\footnotetext{
${ }^{2}$ The distribution of fashion sensitivity is not particularly important here. However, the choice of uniform distribution has two advantages. As it will become clear later, preference evolution implies that the popularity ratio is only implicitly given by Eq 6 that actually defines a fixed point problem. The uniform distribution of $k$ simplifies the solution of the fixed point problem and allows to change the proportion of conformist/anti-conformist agents by modifying the parameters $\underline{k}$ and $\bar{k}$. Other distributions would allow to modify the proportion of conformist/anti-conformist investors in the economy but at the cost of complicating the solution of the fixed point problem.
} 
measured in comparable units.

Finally, it remains to show that preference parameters $\bar{k}, \underline{k}, \bar{s}$ and $\bar{\alpha}$ can be chosen in a such a way that $0 \leq \alpha_{t} \leq 1$ for any $t$. The result is formalized in the next lemma.

Lemma 1 Let $-1 \leq \underline{k} \leq 0$ and $0 \leq \bar{k} \leq 1$, then a sufficient condition for $0 \leq \alpha_{t} \leq 1$ is

$$
\left\{\begin{array}{c}
\bar{\alpha} \leq 1-\bar{k}(1-\bar{s}) \\
\bar{\alpha} \geq \bar{k} \bar{s}
\end{array}\right.
$$

for conformist investors and

$$
\left\{\begin{array}{c}
\bar{\alpha} \leq 1+\underline{k} \bar{s} \\
\bar{\alpha} \geq-\underline{k}(1-\bar{s})
\end{array}\right.
$$

for anti-conformist investors.

Conditions of Lemma 1 are satisfied for example if $\bar{\alpha}=\bar{s}=0.5$. This choice has an intuitive implication because, as we will see, implies that the equilibrium popularity ratio equals $50 \%$ when the supply of the two goods is the same. Thus, if we assume that $\delta_{1,0}=\delta_{2,0}$ then $\alpha_{0}=\bar{\alpha}=50 \%$. In this way, $\bar{\alpha}$ can be interpreted as the initial preference of all investors. In other words, assuming $\bar{\alpha}=\bar{s}=0.5$ is equivalent to saying that at the starting date investors have the same preferences for the two consumption goods. After the initial date, individual preferences will react to changes in the popularity ratio depending on the investor's fashion sensitivity. For this reason, from now on I assume that $\bar{\alpha}=\bar{s}=0.5$. Note that, besides the implications for the initial preferences, there is no special meaning attached to the threshold 50\%. Other thresholds just rescale the rule defined in 5 without qualitatively affecting the economic mechanism behind preferences evolution.

The evolution of individual preferences explains the dynamics of individual consumption baskets. However to understand the impact of preference evolution on aggregate quantities like asset prices we need a measure of aggregate preferences for the two consumption goods. In this framework a natural measure of aggregate preference is repre- 
sented by the average preference defined as

$$
\begin{aligned}
& \frac{1}{\Delta k} \int_{\underline{k}}^{\bar{k}} \alpha_{t}(k) d k \\
& =\bar{\alpha}+0.5 \frac{\Delta k^{2}}{\Delta k}\left(s_{t}-\bar{s}\right) \\
& =0.5\left[1+\frac{\Delta k^{2}}{\Delta k}\left(s_{t}-0.5\right)\right]
\end{aligned}
$$

where $\Delta k^{2}=\bar{k}^{2}-\underline{k}^{2}$. Note that $\Delta k^{2}$ is positive when $\bar{k}^{2}>\underline{k}^{2}$ and negative otherwise. Given the uniform distribution of the fashion sensitivity, the sign of $\Delta k^{2}$ provides information about the distribution of fashion sensitivity in the economy. More precisely, $\Delta k^{2}>0$ $\left(\Delta k^{2}<0\right)$ implies that the majority of investors in the economy are conformist (anticonformist). Accordingly, Eq 7 says that when the majority of investors are conformist, the average preferences evolve in favour of fashionable goods while, when the majority of investors are anti-conformist, the average preferences evolve in favour of out-of-fashion goods.

In summary, the rule of preference evolution given by 4,5 and 6 can be summarized as follows: the more conformist agents see of a given good the more they like it; on the contrary the more anti-conformist agents see of a given good the more they dislike it and the more their preference evolve in favor of less-fashionable goods. This idea is not new in the economic theory. Bell (2002) summarizes the anecdotal and micro-economic evidence in favor of this rule of preference evolution and studies its implications for consumption choices $^{3}$. However, the implications of preference evolution for financial markets have never been studied.

\footnotetext{
${ }^{3}$ It is important to note that the rule of preference evolution is the only similarity between my model and Bell (2002). The economic framework is different. More precisely, Bell (2002) studies a sequence of deterministic 2-period models. At each iterations, agents maximize utility subject to a budget constraint and choose their optimal consumption. When a new iteration starts, agents are endowed with a new supply of endowment and their preferences are updated according to consumption choices of the previous iteration, and so on. Differently, I consider a dynamic model where agents take into account the effect of current choices on the future evolution of preferences. Moreover, I also analyze the implications of preference evolution for portfolio choice and for the properties of financial markets.
} 


\section{The competitive equilibrium}

I solve the model following the standard steps in the literature. First, the optimal consumption rule is obtained by solving the social planner problem. Then, I impose the consumption market-clearing condition and derive the equilibrium state-price density and the relative price of the two consumption goods. Finally, I use the state-price density and the relative price of consumption goods to compute the equilibrium price of traded assets.

Since preference evolution operates through contemporaneous consumption, the social planner problem is considerably more difficult to solve than standard allocation problems of pure-exchange economies. This is so because the investors' optimal consumption depends on the popularity ratio $s_{t}$ which, in turn, depends on the optimal consumption of both goods. As a result, the equilibrium popularity ratio is implicitly defined by the solution of the fixed point problem in Eq 6. To overcome this issue, I proceed as follow: first, I solve for the optimal consumption of the two goods taking $s_{t}$ as given; then, I replace the optimal choice of $c_{1, t}$ and $c_{2, t}$ in 6 and show that the resulting fixed point problem admits a unique solution.

Note that the rule of preference evolution can also be interpreted in the framework of consumption externalities in the spirit of Veblen (1899) and Duesenberry (1949). In the presence of consumption externalities it is not clear whether individual preferences can be aggregated into a representative agent (see Gollier (2004) and García-Peñalosa and Turnovsky (2008)). In the Appendix 6 I show that a heterogeneous agent economy with preference evolution, behaves exactly as the representative agent model analyzed in Section 3.1 below. Therefore, preference aggregation is not an issue in this model.

\subsection{Social planner and optimal consumption}

The social planner distributes the aggregate endowment among agents in a such a way that the consumption allocation is Pareto optimal. Formally, the planner solves

$$
\max _{c_{1, t}(k), c_{2, t}(k)} \mathbb{E} \int_{0}^{\infty} e^{-\rho t}\left[\int_{\underline{k}}^{\bar{k}} g(k) U\left(c_{1, t}(k), c_{2, t}(k)\right) d k\right] d s
$$


subject to the resource constraints

$$
\begin{aligned}
& \int_{\underline{k}}^{\bar{k}} c_{1, t}(k) d k \leq \delta_{1, t} \\
& \int_{\underline{k}}^{\bar{k}} c_{2, t}(k) d k \leq \delta_{2, t}
\end{aligned}
$$

where $U$ is the utility function defined in 4 and $g(k)$ is the social weight attached to the investor with fashion sensitivity $k$. Following Chan and Kogan (2002), I assume that the function $g(k)$ is exogenous and given by ${ }^{4} g(k)=1 / \Delta k, \forall k$. Finally, to keep the problem as simple as possible, investors are equipped with log utility for the two consumption goods.

The assumptions of constant social weights is made to isolate the effect of fashion sensitivity on asset prices. As we will see, homogeneous weights and log utility imply that investors have the same wealth, thus, differences in the investors' consumption strategy can be attributed entirely to differences in the fashion sensitivity. The assumption of $\log$ utility is made for tractability. Thanks to this assumption the fixed point problem 6 admits a unique solution for the popularity ratio. However, the question of existence and uniqueness of the popularity ratio with different utility functions remains open.

Under the assumptions of log utility, uniform social weights and the parametric restriction $\bar{\alpha}=\bar{s}=0.5$, the optimal consumption of the two goods is determined using the martingale method of Karatzas et al. (1987) and is given by

$$
\begin{aligned}
& c_{1 t}\left(k, s_{t}\right)=e^{-\rho t} \frac{0.5+k\left(s_{t}-0.5\right)}{\Delta k \lambda_{t}}, \\
& c_{2 t}\left(k, s_{t}\right)=e^{-\rho t} \frac{0.5-k\left(s_{t}-0.5\right)}{\Delta k p_{t} \lambda_{t}}
\end{aligned}
$$

where $\lambda_{t}$ is the state price density and represents the Arrow-Debreu price of one unit of the numeraire to be delivered at time $t$ in state $\omega$. Similarly, the product $\lambda_{t} p_{t}$ represents the price of one unit of good 2 to be delivered at time $t$ in state $\omega$.

\footnotetext{
${ }^{4}$ The assumption of uniform social weights is less arbitrary than it may appear at a first glance. In fact in Appendix 6 I show that uniform social weights arise endogenously in a decentralized economy where investors have preferences described by $4-5$ and are endowed with the same initial wealth.
} 
$\lambda_{t}$ and $p_{t}$ solve the market clearing conditions of the consumption market and are given in the following proposition.

Proposition 1 Let $\bar{\alpha}=\bar{s}=0.5, g(k)=\frac{1}{\Delta k} \forall k$ and $x_{t}=\delta_{1, t} / \delta_{2, t}$. Then,

$$
\begin{gathered}
\lambda_{t}=e^{-\rho t} \frac{\left(\Delta k+\Delta k^{2}\left(s_{t}-0.5\right)\right)}{2 \Delta k \delta_{1, t}}, \\
p_{2, t}=\frac{\Delta k-\Delta k^{2}\left(s_{t}-0.5\right)}{\Delta k+\Delta k^{2}\left(s_{t}-0.5\right)} x_{t}
\end{gathered}
$$

where $\Delta k^{2} \equiv \bar{k}^{2}-\underline{k}^{2}$.

Using the definition of average preferences given in (7) we can rewrite the relative price $p_{2, t}$ as

$$
p_{2, t}=\underbrace{\frac{\frac{1}{\Delta k} \int_{\underline{k}}^{\bar{k}}\left(1-\alpha_{t}\right) d k}{\frac{1}{\Delta k} \int_{\underline{k}}^{\bar{k}} \alpha_{t} d k}}_{\text {Preference effect }} \times \underbrace{x_{t}}_{\text {Supply effect }}
$$

Equation 11 says that the relative price is the product of two quantities: the relative preferences for the two consumption goods and the relative endowment. The dependence of the relative price on the supply of the two goods is standard in models with multiple consumption goods and captures customary supply effects: when the supply of good 1 increases, good 2 becomes relatively more scarce and, all else equal, its price increases to allow for market clearing. The relative price also depends on the relative preference for the two goods. An increase in the average preference for good 1 (2) increases the demand for good 1 (2) and, all else equal, raises the price of good 1 (2) relative to that of good 2 (1). The effect of preference evolution on the relative price of consumption goods is new and not present in models with constant preferences.

Finally, plugging the equilibrium values of $\lambda_{t}$ and $p_{t}$ into the optimal consumption 9 and 10 gives the investors' consumption share as a function of the popularity ratio:

Corollary 2 Under the parametric assumptions of Proposition 1 the consumption shares 
of the two goods are given by

$$
\begin{aligned}
& \frac{c_{1 t}}{\delta_{1, t}}\left(k, s_{t}\right)=\frac{1+2 k\left(s_{t}-0.5\right)}{\Delta k+\Delta k^{2}\left(s_{t}-0.5\right)}, \\
& \frac{c_{2 t}}{\delta_{2, t}}\left(k, s_{t}\right)=\frac{1-2 k\left(s_{t}-0.5\right)}{\Delta k-\Delta k^{2}\left(s_{t}-0.5\right)}
\end{aligned}
$$

with the following properties

$$
\begin{aligned}
& \lim _{s_{t} \rightarrow 1} \frac{c_{1 t}}{\delta_{1, t}}\left(k, s_{t}\right)=\frac{1+k}{\Delta k+0.5 \Delta k^{2}}, \quad \lim _{s_{t} \rightarrow 1} \frac{c_{2 t}}{\delta_{2, t}}\left(k, s_{t}\right)=\frac{1-k}{\Delta k-0.5 \Delta k^{2}} \\
& \lim _{s_{t} \rightarrow 0} \frac{c_{1 t}}{\delta_{1, t}}\left(k, s_{t}\right)=\frac{1-k}{\Delta k-0.5 \Delta k^{2}}, \quad \lim _{s_{t} \rightarrow 0} \frac{c_{2 t}}{\delta_{2, t}}\left(k, s_{t}\right)=\frac{1+k}{\Delta k+0.5 \Delta k^{2}} .
\end{aligned}
$$

Several interesting implications emerge from Corollary 1. First, consumption shares are not monotone in the popularity ratio as one may expect. Consider for instance the consumption share of the first good (i.e. $c_{1} / \delta_{1, t}$ ). It is easy to show analytically that the consumption share increases with $s_{t}$ if and only if $k>\frac{\Delta k^{2}}{2 \Delta k}$. To understand the economic meaning of this expression assume, for instance, that $k>0$ so that the investor is conformist. When deciding his/her optimal consumption the conformist investor faces a trade-off between his/her desire to consume the popular good and the price of the good. As explained above, the relative price of consumption goods increases with their popularity. Therefore, only investors very sensitive to fashions are willing to pay a higher price to buy fashionable goods. Investors less sensitive to fashions may decide to purchase less fashionable but cheaper goods. The cut-off level of fashion sensitivity depends on the distribution of investors: the higher is the fraction of conformist investors relative to the total mass of investors (i.e. the higher is the ratio $\frac{\Delta k^{2}}{2 \Delta k}$ ) the higher is the price increase when the popularity of goods rises and, as a result, the higher has to be the fashion sensitivity to convince the investor to buy popular goods.

These results raise the question of whether preference evolution leads to polarization in consumption choices. The limit values of consumption shares in Corollary 2 suggest the only investors very sensitive to fashion (i.e. investors with fashion sensitivity either 1 or -1 ) find it optimal to consume one good exclusively in response to change in the 
popularity of goods. For instance, a conformist investor with $k=1$ will choose to consume good 1 exclusively, and nothing of good 2, when $s_{t}$ goes to 1 . Other conformist investors will take into account the above mentioned trade-off between price and popularity of fashionable goods and hold diversified consumption baskets. This differs from Bell (2002) where preference evolution unambiguously leads to polarized consumption choices.

\subsection{The equilibrium popularity ratio}

The previous sections analyses consumption choices for a given level of the popularity ratio, thus, ignoring its endogenous nature. The next proposition characterizes the equilibrium value of the popularity ratio and its main properties.

Proposition 2 Let $\bar{\alpha}=\bar{s}=0.5, g(k)=\frac{1}{\Delta k} \forall k$ and $x_{t}=\delta_{1, t} / \delta_{2, t}$. The, the popularity ratio $s_{t}$ is the unique solution to the equation

$$
F\left(s_{t}, x_{t}\right)=\frac{1}{\Delta k}\left[f\left(s_{t}, x_{t}, \bar{k}\right)-f\left(s_{t}, x_{t}, \underline{k}\right)\right]=0
$$

where

$$
f\left(s_{t}, x_{t}, y\right)=\frac{p_{2, t}}{p_{2, t}-1}\left[y+\frac{\log \left(\frac{0.5\left(1+p_{2, t}\right)}{0.5\left(1+p_{2, t}\right)+y\left(p_{2, t}-1\right)\left(s_{t}-0.5\right)}\right)}{\left(p_{2, t}-1\right)\left(s_{t}-0.5\right)}\right] .
$$

Moreover,

$$
\frac{\partial s_{t}}{\partial x_{t}}>0, \quad \lim _{x_{t} \rightarrow \infty} s_{t}=1, \quad \lim _{x_{t} \rightarrow 0} s_{t}=0
$$

The popularity ratio increases with the relative supply of the two goods $x_{t}$. This is mainly an effect of the market clearing mechanism that incentives consumption of abundant goods. In other words, in this economy popular goods are abundant goods. When a good experiences a positive supply shocks, its popularity increases and preferences evolve depending on the distribution of investors in the economy: when the majority of investors are conformist, preferences evolve in favour of abundant goods while, when the majority of investors are anti-conformist, preferences evolve in favour of scarce goods . The link between supply shocks and preference evolution sheds further light on the dynamics of the relative price of consumption goods. When the majority of investors are conformist 
a positive shock to the relative supply of good 1 (i.e a shock to $x_{t}$ ) has two counteractive effects on the relative price of consumption goods. On the one hand, market clearing forces induce the relative price of good 2 to increase. On the other hand, the positive shock to the relative supply of good 1 increases its popularity and, in turn, induces the relative price of good 2 to decrease. Naturally, the final effect on the relative price will depend on the sum of the two opposite forces. Differently, when the majority of investors are anti-conformist, the market clearing forces and the change in preferences induced by the positive shock to $x_{t}$ reinforce with each others and unambiguously increase the price of scarce goods.

\subsection{Implications of heterogeneity and preference evolution for equilibrium outcomes}

Accounting for heterogeneity is important because it allows me to incorporate the effect of different attitudes toward fashion into asset prices. To provide additional insights into the implications of heterogeneity, the following Corollary shows the equilibrium outcomes in a simple economy where all investors have the same fashion sensitivity.

Corollary 3 Let $\bar{\alpha}=\bar{s}=0.5, x_{t}=\delta_{1, t} / \delta_{2, t}$, and assume that all agents feature the same fashion sensitivity $k$. Then, we have

$$
\begin{aligned}
c_{1 t}\left(k, s_{t}\right) & =e^{-\rho t} \frac{0.5+k\left(s_{t}-0.5\right)}{\lambda_{t}} \\
c_{2 t}\left(k, s_{t}\right) & =e^{-\rho t} \frac{0.5-k\left(s_{t}-0.5\right)}{p_{2, t}\left(s_{t}\right) \lambda_{t}\left(s_{t}\right)}
\end{aligned}
$$

where

$$
\begin{aligned}
\lambda_{t}\left(s_{t}, \delta_{1, t}\right) & =e^{-\rho t} \frac{\left(0.5+k\left(s_{t}-0.5\right)\right)}{\delta_{1, t}} \\
p_{2, t}\left(s_{t}, x_{t}\right) & =\frac{\left(0.5-k\left(s_{t}-0.5\right)\right)}{\left(0.5+k\left(s_{t}-0.5\right)\right)} x_{t}
\end{aligned}
$$


and the popularity ratio is

$$
s_{t}=\frac{\delta_{1, t}}{\delta_{1, t}+\delta_{2, t}}
$$

Corollary 3 shows that the homogeneous economy is observational equivalent to an economy where the popularity ratio $s_{t}$ (and thus the evolution of the investor's preferences) is exogenously determined by the dividend share only. In this economy, the consumption basket of the representative investor equals the dividend share of the good 1 and is therefore biased toward abundant goods. This happens even if the representative investor is anti-conformist, which seems counter-intuitive. In a heterogeneous economy, the popularity ratio $s_{t}$ represents the average consumption basket which now differs from individual consumption baskets. As a result, even if the average consumption basket is biased toward abundant goods, individual consumption baskets reflect individual preferences and are therefore biased toward the preferred good, depending on the degree of fashion sensitivity $k$.

Finally, in order to emphasize the importance of fashion sensitivity, I report below the key equilibrium quantities in a benchmark economy with constant log-linear preferences.

Corollary 4 Let $\bar{\alpha}=0.5, x_{t}=\delta_{1, t} / \delta_{2, t}$ and assume that all agents are characterized by constant log-linear preferences (i.e. $k=0$ ). Then, the equilibrium optimal consumption is given by

$$
\begin{aligned}
c_{1 t}(k) & =e^{-\rho t} \frac{0.5}{\lambda_{t}} \\
c_{2 t}(k) & =e^{-\rho t} \frac{0.5}{p_{2, t} \lambda_{t}}
\end{aligned}
$$

where

$$
\begin{aligned}
\lambda_{t} & =e^{-\rho t} \frac{0.5}{\delta_{1, t}} \\
p_{2, t} & =x_{t} .
\end{aligned}
$$

In absence of fashion sensitivity, the optimal consumption of the two goods is a nonrandom fraction of dividend payments. In addition the relative price of the two goods 
equals the relative supply of the two consumption goods. Cass and Pavlova (2004) show that when the two previous condition hold the volatility matrix of the two risky assets is not invertible and therefore financial markets are not complete. Differently, when investors are sensitive to fashions, the optimal consumption and the relative price of consumption goods depend not only on the supply of the two goods but also on their popularity (Proposition 1). As we will see in section 4.2 below, the dependence of equilibrium quantities on the popularity ration makes the volatility matrix invertible ans, thus, renders market complete even when investors are equipped with log-linear preferences over multiple consumption goods.

\subsection{Financial assets}

Market completeness implies the existence of unique state price density $\lambda_{t}$ with dynamics:

$$
d \lambda_{t}=-\lambda_{t}\left(r_{t} d t+\theta_{1} d B_{1, t}+\theta_{2} d B_{2, t}\right)
$$

where $r_{t}$ is the instantaneous risk-less rate and $\theta_{i}$ (with $i=1,2$ ) is the market price of risk and represents the expected instantaneous return on a claim with unit exposure to the Brownian motion $B_{i}$. Applying Itô's lemma to $\lambda_{t}$ and comparing coefficients with Eq (13) gives the equilibrium risk-less rate and market prices of risk reported in the next Proposition.

Proposition 3 Under the assumptions of Proposition 1, the instantaneous risk-less rate is given by

$$
r_{t}=\rho+\nu_{1}-\phi_{1}^{2}-\frac{\Delta k^{2} x_{t}}{\Delta k+\Delta k^{2}\left(s_{t}-0.5\right)} \frac{\partial s_{t}}{\partial x_{t}}\left(\nu_{1}-\nu_{2}+\phi_{2}^{2}\right)-\frac{\Delta k^{2} x_{t}^{2}}{\Delta k+\Delta k^{2}\left(s_{t}-0.5\right)} \frac{\partial^{2} s_{t}}{\partial x_{t}^{2}} \frac{\phi_{1}^{2}+\phi_{2}^{2}}{2} .
$$

The market prices of risk are

$$
\begin{aligned}
\theta_{1} & =\phi_{1}\left(1-\frac{\Delta k^{2} x_{t}}{\Delta k+\Delta k^{2}\left(s_{t}-0.5\right)} \frac{\partial s_{t}}{\partial x_{t}}\right), \\
\theta_{2} & =\phi_{2} \frac{\Delta k^{2} x_{t}}{\Delta k+\Delta k^{2}\left(s_{t}-0.5\right)} \frac{\partial s_{t}}{\partial x_{t}} .
\end{aligned}
$$


The first three elements of the risk free rate are standard in economies economy in which all investors have constant log-linear preferences and represent the investor's impatience $(\rho)$, the growth rate of the numeraire $\left(\nu_{1}\right)$ and the desire of precautionary saving due to the uncertainty in the numeraire good $\left(\phi_{1}^{2}\right)$. The second and the third term are new and entirely due to preference evolution. In a standard economy with constant log-linear preferences, the risk-less rate makes investors indifferent between consuming the numeraire today or tomorrow. When the expected growth of the numeraire good is high, the future marginal utility is expected to be lower than the current marginal utility and investors desire to borrow in order to anticipate consumption, thus, driving up the risk free rate. When preferences are time-varying, there is an additional reason why the marginal utility changes over time. Namely, the utility function itself changes in response to shocks in the popularity of consumption goods. The fourth term on the left hand side of Eq 14 reflects this effect. When preference change over time, investors also have additional precautionary saving motives as compared to the case of constant preferences and save more today to hedge the risk of unexpected changes in future preferences. This effect is captured by the last term of Eq 14 .

Preference evolution also alters the required compensation for bearing supply shocks (i.e., $\theta_{1}$ and $\theta_{2}$ ). Shocks to the supply of consumption goods command a premium to the extent that they are negatively correlated with the marginal utility of the numeraire good $\left(\lambda_{t}\right)$. Consider first an economy where the majority of investors are conformist (i.e. $\Delta k^{2}>$ 0). Eq 15-16 say that conformist behavior decreases the investors' required compensation for shocks to the supply of good 1 while it increases the required compensation for shocks to the supply of good 2, as compared to the case of constant log-linear preferences. This happens because conformist behavior increases the correlation between shocks to the supply of the numeraire good and its marginal utility while, at the same time, decreases the correlation between shocks to the supply of good 2 and the marginal utility of the numeraire. For instance, a positive shock to $\delta_{1}$ decreases the marginal utility of the numeraire, in exactly the same way as in the economy with constant preferences (i.e., it increases the denominator of $\lambda_{t}$ ). In addition, when preferences change over time, 
the positive shock to $\delta_{1}$ also increases the popularity ratio $s_{t}$ which, in turn, increases the marginal utility of the numeraire good. These two opposite effects increase the correlation between shocks to the numeraire good and its marginal utility and therefore decrease $\theta_{1}$ as compared to the case of constant preferences.

When preferences are constant, shocks to the supply of good 2 are not priced because they do not affect the marginal utility of the numeraire. When preferences evolve over time, shocks to the supply of good 2 affect the marginal utility of the numeraire via their effect on the average preferences: a positive shock to $\delta_{2}$ decreases the popularity ratio $s_{t}$ which, in turn, decreases the marginal utility of the numeraire. This induces a negative correlation between shocks to the supply of good 2 and the marginal utility of the numeraire and implies that conformist behavior increases $\theta_{2}$ as compared to an economy with constant preferences. When the majority of investors are anti-conformist (i.e. $\Delta k^{2}<0$ ), the above arguments can be reversed to explain why anti-conformist behavior increases the investors' required compensation for shocks to the supply of good 1 and decreases the required compensation for shocks to the supply of good 2 , as compared to the case of constant log-linear preferences.

The value of the risky assets and the value of the entire stock market ( i.e. the price of the asset paying the total stream of consumption) can be determined using the state price density and the relative price of the two goods given in Proposition 1.

Proposition 4 Under the parametric assumptions of Proposition 1, the price-dividend ratio of the asset that pays the dividend stream $\delta_{1}$ is

$$
\frac{S_{1, t}}{\delta_{1, t}}=\frac{\frac{\Delta k-0.5 \Delta k^{2}}{\rho}+\Delta k^{2} \int_{t}^{\infty} e^{-\rho(s-t)} \mathbb{E}_{t}\left[s_{s}\right] d s}{\Delta k+\Delta k^{2}\left(s_{t}-0.5\right)}
$$

and the price-dividend ratio of the asset with dividend stream $\delta_{2}$ is

$$
\frac{S_{2, t}}{p_{2, t} \delta_{2, t}}=\frac{\frac{\Delta k+0.5 \Delta k^{2}}{\rho}-\Delta k^{2} \int_{t}^{\infty} e^{-\rho(s-t)} \mathbb{E}_{t}\left[s_{s}\right] d s}{\Delta k-\Delta k^{2}\left(s_{t}-0.5\right)}
$$


Finally,

$$
\begin{aligned}
& \lim _{s_{t} \rightarrow 0} \frac{S_{1, t}}{\delta_{1, t}}=\lim _{s_{t} \rightarrow 0} \frac{S_{2, t}}{p_{2, t} \delta_{2, t}}=\frac{1}{\rho} \\
& \lim _{s_{t} \rightarrow 1} \frac{S_{1, t}}{\delta_{1, t}}=\lim _{s_{t} \rightarrow 1} \frac{S_{2, t}}{p_{2, t} \delta_{2, t}}=\frac{1}{\rho}
\end{aligned}
$$

To interpret the expression for the price-dividend ratios, recall that in a standard economy with constant log-linear preferences the price price-dividend ratio of both assets equals the constant value $1 / \rho$. Thus, preference evolution makes the price dividend ratios stochastic and time-varying as compared to the case of constant log-linear preferences. Moreover, the price dividend ratios of a standard economy with constant log preferences are obtained as limiting case when the popularity ratios goes to either 0 or 1 . The latter result implies that the price dividend ratios are well defined at the endpoint of $s_{t}$. This stands in contrast with single consumption good economies where price-dividend ratios of assets whose dividend share goes to zero may diverge to infinity (see Cochrane et al. (2008) for more details on this point).

Finally, the price of the market portfolio $S_{M, t}$ is given by,

$$
\begin{aligned}
& S_{M, t}=\mathbb{E}_{t}\left[\int_{t}^{\infty} \frac{\lambda_{s}}{\lambda_{t}}\left(\delta_{1, s}(k)+p_{2, s} \delta_{2, s}(k)\right) d s\right] \\
& =\frac{\delta_{t}^{1}+p_{2, t} \delta_{t}^{2}}{\rho}
\end{aligned}
$$

which implies that the price-dividend ratio of the market equals the constant $1 / \rho$, as expected in case of log utility. In other words, preference evolution affects the valuation ratios of sectoral equity only but not the valuation ratio of the entire stock market which does not differ with respect to the case of constant log-linear preferences. 


\subsection{Individual wealth and portfolio policy}

The wealth $w_{t}^{k}$ of an investor with fashion sensitivity $k$ is defined as the present value of the discounted consumption stream:

$$
w_{t}^{k}=\mathbb{E}_{t}\left[\int_{t}^{\infty} \frac{\lambda_{s}}{\lambda_{t}}\left(c_{1, s}(k)+p_{2, s} c_{2, s}(k)\right) d s\right]=\frac{S_{M, t}}{\Delta k}
$$

Eq 20 says that individual wealth is a constant multiple of the price of the market portfolio (i.e. the total wealth in the economy) and, as a result, does not differ across investors.

The investor's optimal portfolio follows from the applications of the Itô's lemma on financial wealth 20

$$
\begin{aligned}
d w_{t} / w_{t}= & {[\ldots] d t+\phi_{1} \overbrace{\left(1-\frac{\Delta k^{2} x_{t}}{\Delta k+\Delta k^{2}\left(s_{t}-0.5\right)} \frac{\partial s_{t}}{\partial x_{t}}\right)}^{\theta_{1}} d B_{1, t} } \\
& +\phi_{2} \underbrace{\frac{\Delta k^{2} x_{t}}{\Delta k+\Delta k^{2}\left(s_{t}-0.5\right)} \frac{\partial s_{t}}{\partial x_{t}}}_{\theta_{2}} d B_{2, t}
\end{aligned}
$$

where the superscript $k$ is omitted since financial wealth does not depend on fashion sensitivity. Denoting by $\pi_{1}$ and $\pi_{2}$ the fraction of wealth invested in asset 1 and 2 , respectively, we can rewrite the dynamics of wealth as

$$
d w_{t} / w_{t}=[\ldots] d t+\left(\pi_{1} \sigma_{1,1}+\pi_{2} \sigma_{2,1}\right) d B_{1, t}+\left(\pi_{1} \sigma_{1,2}+\pi_{2} \sigma_{2,2}\right) d B_{2, t}
$$

where $\sigma_{i, j}$ indicates the exposure of asset $i$ return to the risk factor $B_{j}$ with $i, j=1,2$. Portfolio weights are determined by comparison of Eq's 21 and 22:

$$
\left(\begin{array}{c}
\pi_{1} \\
\pi_{2}
\end{array}\right)=\Sigma^{-1}\left(\begin{array}{c}
\theta_{1} \\
\theta_{2}
\end{array}\right) .
$$

where $\Sigma=\left(\begin{array}{cc}\sigma_{11} & \sigma_{21} \\ \sigma_{12} & \sigma_{22}\end{array}\right)$ is the volatility matrix in the representation of the investment opportunity set. This matrix is crucial for market completeness. More precisely, if $\Sigma$ is 
invertible, financial markets are complete. In case it is not, the returns of the two assets are linearly dependent and markets are incomplete. In the latter case, the optimal policies $\pi_{1}$ and $\pi_{2}$ that finance consumption strategies of Proposition 1 cannot be computed. In the next Section I show numerically that the determinant of the volatility matrix is always different than 0, which implies that financial markets are complete.

By inspection of Eq's 20 -22 we note that equity portfolios are the same across investors. In other words, log-utility and fashion sensitivity create herd behaviour in equity investments in the sense that investors follow each other into the same risky asset. This result has a clear economic explanation. In a pure-exchange economy the optimal portfolio has to finance the total investor's consumption which is given by

$$
c_{1, t}(k)+p_{2, t} c_{2, t}(k)=\frac{\delta_{1, t}+p_{2, t} \delta_{2, t}}{\Delta k} .
$$

The previous equation shows that total consumption does not depend on individual preferences but only on aggregate preferences through the relative price $p_{2, t}$. In other word, investors with time-varying log-linear preferences herd in the sense that they have the same total consumption and, thus, hold the same portfolio of risky assets whose dynamics depends on the evolution of average preferences only. This result is the key to understand the dynamics of optimal portfolios analyzed in section 4.2

\section{Model implications}

In this Section I study the implications of preference evolution for the dynamics of stock returns and investors' portfolios. To determine the dynamics of the quantities of interest, it is necessary to select parameter values for the sectoral dividend processes and the investors' preferences. As a benchmark case I specify symmetric dividend parameters: 2 percent mean dividend growth and 20 percent standard deviation, that is, $\nu_{i}=0.02$ and $\phi_{i}=0.2$ for $i=1,2$. Then, holding fixed the parameters of the second dividend process at the previous values, I set the parameters of the first dividend process to twice the previous values, $\nu_{1}=0.04$ and $\phi_{1}=0.4$. The first parametrization corresponds to the 
"symmetric" case and the second to the "risky asset" case of Cochrane et al. (2008) . To study the implications for asset prices of fashion sensitivity I set $\underline{k}=-0.5$ and $\bar{k}$ equal to either .1 or 1 . The first case corresponds to an economy where about $90 \%$ of investors are anti-conformist. The second case corresponds to an economy in which about $90 \%$ of investors are conformist.

It is worth mentioning the model relies on some simplifying assumptions assumptions as, for instance, log utility and uniform social weights (which together imply uniform initial wealth) and therefore is not meant to quantitatively match the empirical asset pricing properties. Instead my main goal is to show that a simple and intuitive modification of the standard framework helps to reproduce features of investors' portfolios and stock returns that would otherwise be difficult, if not impossible, to obtain in an economy characterized by the simple ingredients listed above.

\subsection{The dynamics of the popularity ratio}

Figure 8.1 shows the drift and the diffusion of the popularity ratio. The drift of the popularity ratio is zero when $s_{t}=0$ or $s_{t}=1$, positive for small values of $s_{t}$ and negative for large values of $s$. Thus, the drift term induces mean reversion in the preferences for the two consumption goods. However, the drift term is quite small which implies the popularity ratio is highly persistent. The volatility of the popularity ratio is largest when $s_{t}=.5$ and declines to zero at $s_{t}=0$ or $s_{t}=1$. This is so because the popularity ratio is an increasing function of the dividend share of asset 1 (Proposition 2) and thus inherits the dynamics of the the dividend share process ${ }^{5}$.

Note that the distribution of the popularity ratio is not stationary. The non stationarity of the popularity ratio comes from the non stationarity of the dividend shares: given that the two dividends are modelled as geometric Brownian motions, one of the two sectors will eventually dominate the other. When this happens, the popularity ratio will reach its limit values (0 or 1$)$. These limit values are absorbing states, in the sense that, once the economy reaches one of them, it stays there forever. However, this only

\footnotetext{
${ }^{5}$ see Cochrane et al. (2008) for a detailed discussion on the properties of the drift and the diffusion coefficient of dividend shares.
} 
happens when the relative endowment $x_{t}$ goes either to 0 or $\infty$, that is only in the limit when $t \longrightarrow \infty$. Cochrane et al. (2008) show via simulations that the non stationarity of the dividend share does not affect asset prices ${ }^{6}$. In addition, as long as investors are heterogeneous in their fashion sensitivity, average preferences will be diversified across the two goods even at the limit values of the popularity ratio. From an economic point of view the non stationarity of the popularity ratio implies that one of the companies (or sector) will eventually become extremely popular and the other disappears. This interpretation might make the non-stationarity property of the model less puzzling. Indeed, we frequently observe that some commercial products disappear in response to change in investor preferences. Think for instance about the transition from Beta to VHS and finally to DVD video formats or more recently, to the increasing popularity gained by the iPhone (or by Samsung mobile phones) at the expense of more traditional mobile phones such as Nokia or Motorola.

\subsection{Portfolio holdings}

The recent empirical asset pricing literature has documented that individual investors tend to hold concentrated and under diversified portfolios of stocks. French and Poterba (1991) show that investors' portfolios are biased toward domestic stocks. Grinblatt and Keloharju (2001), Feng and Seasholes (2004), Ivković and Weisbenner (2005, 2007) and Seasholes and Zhu (2010) provide evidence in favour of a local bias in investors' portfolios. Hong et al. (2004, 2005) find evidence of conformist behavior in households' and fund managers' portfolios. This evidence is difficult to rationalize in general equilibrium asset pricing models and is also in stark contrast with the popular financial advice to hold well-diversified portfolios. In this section I use the concept of endogenous preferences evolution and fashion cycles to explain the previous empirical findings.

Before analyzing portfolios in detail, I address the question of market completeness.

\footnotetext{
${ }^{6}$ More precisely, they show that, for the parameter values of the dividend processes used in their simulation (which are the same as those of my model), there is only a negligible probability that the dividend share is below 0.05 or above 0.95 after 100 years. Given that the discount rate applied to dividends beyond 100 years is very high, they conclude that the non stationarity of the dividend share has only a negligible effect on asset prices.
} 
In a continuous time market with two Brownian motions and two risky assets, market completeness requires the volatility matrix of the risky assets to be invertible. Figure 8.2 shows that the determinant of the volatility matrix is always different than zero except at the extremes of the popularity ratio $s_{t}$ where the preferences for the two consumption goods becomes constant and the model is equivalent to a standard log-linear economy where financial markets are incomplete. This implies that the peculiar equilibria of Cass and Pavlova (2004) arise in the limiting case where $s_{t}$ goes either to 0 or 1 and preferences become constant. As a result, log-preferences can be used in models with multiple consumption goods while at the same time preserving market completeness. A different approach to preserve market completeness under log-linear preferences has been suggested by Pavlova and Rigobon (2007). They build a model where agents have log-linear preferences for two consumption goods but they are subject to demand shocks. From a technical point of view the demand shocks play the same role of the popularity ratio in ensuring market completeness. However, while demand shocks are exogenous processes the popularity ratio in my model is endogenous and determined by the investors' optimal consumption choices.

Having established that financial markets are complete, I study portfolio holdings as a function of the popularity ratio $s_{t}$ (Figure 8.3). From Section 3.5 we know that investors equipped with time-varying log-linear preferences herd in their investment decisions and hold the same portfolio whose dynamics depends on the evolution of aggregate preferences. When the majority of investors are conformist, aggregate preferences evolve in favour of fashionable goods and, as a result, investors' portfolios are biased toward stocks of sectors that produce popular goods. Similarly, when the majority of investors are anticonformist, aggregate preferences evolve in favour of out-of-fashion goods and investors' portfolios are biased toward stocks of sectors that produce out-of-fashion goods. Thus, fashion sensitivity generates local biases in investors' stock allocation.

Portfolio concentration can also be explained by relative wealth concerns (Garcia and Strobl (2011)) or by asymmetric information about the performance of local and non-local equity indices (Gehrig (1993) and Brennan and Cao (1997)) or about the performance 
of local and non-local individual stocks (Hatchondo (2008)). The dynamics of optimal portfolios generated by preference evolution is similar but the economic mechanism behind portfolio concentration is different. In my model, optimal portfolios have to finance the investors' total consumption plan that in turn depends on the evolution of average preferences. Thus, the portfolio re-balancing strategy fully reflects changes in the average preferences for the two consumption goods. When the majority of investors are conformist, investors prefer popular goods because they allow them to conform to the consumption choices of other agents. As a results, optimal portfolios are biased toward stocks of firms producing popular goods. Differently, when the majority of investors are anti-conformist, investors prefer un-popular goods because they allow for differentiation from the consumption choices of other people and, as a result, invest more wealth in firms producing un-popular goods. Portfolio concentration has also been explained using the concepts of cultural similarities and word-of-mouth communication. My model suggests that cultural similarities and word-of-mouth communication are important to the extent they facilitate the diffusion of fashions among investors and induce preferences for consumption goods to change over time.

Huberman (2001) argues that portfolio concentration can be explained by familiarity, that is, the investors' tendency to favour stocks they know the most. In particular, he finds that customers of the U. S. Regional Bell Operating Companies (RBOC) tend to buy shares of the local RBOC rather than shares of any other RBOC. Because each RBOC is the major provider of local telephone service in its region, the results of Huberman (2001) can be rationalized in a model with preference evolution and conformist investors. However, the economic idea behind fashion sensitivity and preference evolution is more general than familiarity. First, the results of Huberman (2001) point toward a geographical concept of familiarity. Differently, in my model, the popularity of consumption goods may change for reasons other than geographical distance. Second, the concept of familiarity might be unable to explain the choice between substitute goods. After all, in case of two substitute goods, it is difficult to argue that individuals know one of the two better than the other. In this case, it more likely that individuals have the same knowledge about 
the two goods and thus their consumption choice should be explained by something else besides familiarity. Fashion sensitivity could offer an explanation for the choice between substitute goods.

\subsection{Risk free rate and Equity premium}

Figure 8.4 shows the instantaneous risk-free rate as a function of the popularity ratio $s_{t}$. The risk-free rate makes investor indifferent between consuming the numeraire today or consuming the numeraire tomorrow. When the majority of investors are conformist, the marginal utility of the numeraire good increases with its popularity. As a result, for low values of the popularity ratio (which measures the popularity of the numeraire good), investors save more today for consuming the numeraire good tomorrow, thus, decreasing the risk-free rate. Instead, for large values of the popularity ratio, average preferences are biased toward the numeraire good, and investors borrow more for consuming the numeraire today, thus, increasing the risk-free rate. When the majority of investors are anti-conformist the economic mechanism described above is reversed. As a result, the risk-free is largest for low values of the popularity and decreases when the popularity ratio increases.

These results imply that preference evolution introduces time variation in the risk free rate as compared to the case of constant log-linear preference. Consistent with empirical data the variation of the risk free rate is not excessive. For instance, in the symmetric case the risk free rate fluctuates in between $0.8 \%$ and $1.2 \%$ when the majority of investors are conformist and between $0.9 \%$ and $1.1 \%$ when the majority of investors are anti-conformist. In the asymmetric case, the volatility of the popularity ratio increases and the additional precautionary saving motives induce the risk free rate to became negative but its variation is still small and comparable to that observed in the symmetric case.

In Figure 8.5 I analyze the implications of preference evolution for excess returns of risky assets. Log-utility makes the two assets positively correlated which implies that the dynamics of expected returns of the two assets looks similar. Thus, for brevity, I report the excess returns of asset 1 , the excess return of the market and the difference between 
the excess returns of the two assets.

When the majority of investors are conformist, preference evolution produces a Ushaped relationship between excess returns and popularity ratio. The economic intuition for this result is the following. Conformist investors chose consumption in a such a way to minimize the distance between their consumption basket and the average consumption basket in the economy. Naturally, this distance is minimized when $s_{t}=0.5$ because at this point all agents have the same consumption basket. In other words, the equity premium is the reward required to compensate conformist agents for the risk that their consumption diverges from the average consumption in the economy. When the majority of investors are anti-conformist, the relationship between returns and popularity ratio becomes inverted U-shaped. This is so because anti-conformist agents select consumption in order to maximize the distance between their consumption basket and the average consumption basket in the economy. As a result, they require a larger premium when this distance is smaller, that, is when $s_{t}=0.5$. This suggests that, when the majority of agents are anti-conformist, the equity premium is the reward required to compensate anti-conformist agents for the risk that their consumption becomes similar to the average consumption in the economy.

Beside expected returns of individual assets it is also important to study return differential between different assets. The second panel of Figure 8.5 shows that conformist investors require a larger premium for investing in asset 1 while anti-conformist investors require a larger premium for investing in asset 2. Stock returns depend on the correlation between dividend shocks and the consumption of the numeraire. When the majority of investors are conformist, average preferences evolve in favour of abundant goods. After a positive shock to $\delta_{1}$ (the supply of the numeraire consumption good) the aggregate consumption of the numeraire good has to increase. As a result, shock to the supply of the numeraire good are positively correlated with the consumption of the numeraire. Differently, shocks to $\delta_{2}$ (the supply of good 2) decrease the average preference, and thus the aggregate consumption, of the numeraire good. As a result, shocks to the supply of good 2 are negatively correlated with the consumption of the numeraire good. In summary, 
from the perspective of conformist investors asset 1 is riskier because its dividend is more correlated with the consumption of the numeraire good than the dividend paid by asset 2. For this reason, conformist investors require higher rates of return to invest in asset 1 than in asset 2. Instead, from the perspective of anti-conformist investors asset 1 is less risky because its dividend is less correlated with the consumption of the numeraire good than the dividend paid by asset 2. For this reason, anti-conformist investors require higher rates of return to invest in asset 2 than in asset 1 . Finally note that with constant log-linear preferences stock returns are equalized across different assets. Thus, differences in sectoral returns are entirely due to preference evolution.

\subsection{Value and growth effect}

In their seminal paper Fama and French (1992) documented that in the US market stocks with low market-to-book ratio pay higher returns. This finding is in contrast with the standard CAPM of Sharpe (1964) and Lintner (1965) because empirically value stocks do not have higher betas than growth stocks. Since then researchers have developed an increasing number of theoretical model attempting to explain the value premium puzzle. For instance Lettau and Wachter (2007) and Croce et al. (2014) propose an explanation of the value premium based and the different cash flows duration of value and growth stocks. Differently, Chen (2014) shows that cash flows of growth stocks tend to grow more slowly than value stocks. This suggests that the duration based argument might not be the only explanation of the value premium puzzle. It is therefore instructive to explore the implications of preference evolution for the value premium puzzle.

Consider first an economy where the majority of agents are conformist. Figure 8.6 shows that for low values of the popularity ratio, asset 1 has higher valuation than asset 2 while the opposite is true for high values of the popularity ratio. The intuition for this result is simple: when the popularity ratio increases, the future marginal utility of good 1 is expected to increase while at the same time the future marginal utility of good 2 is expected to decrease. For sufficiently large values of the popularity ratio, the future marginal utility of good 1 increases more than the current marginal utility. As a result, 
investors would like to postpone consumption of good 1 and expedite the consumption of good 2, thus depressing the valuation of asset 1 as compared to that of asset 2 . This result, in conjunction with the premium paid by asset 1 over asset 2 , implies that conformist behavior generates a growth premium for low values of the popularity ratio and a value premium for high value of the popularity ratio. In the risky asset case, the value premium is even more evident because asset 1 has higher valuation over almost the entire range of the popularity ratio. This is so because in the risky asset case good 1 has higher expected growth rate and higher standard deviation than asset 2 . Therefore the expected marginal utility of good 1 grows faster (and the expected marginal utility of asset 2 decreases faster) than in the symmetric case. As a result, investors would like to postpone consumption of good 1 and expedite the consumption of good 2 by more and even for lower values of the current popularity ratio than in the symmetric case.

Differently, when the majority of investors are anti-conformist, the value premium arises when consumption goods have low popularity. In this case, claims to consumption goods with low risk-return profile tend to have at the same time low price-dividend ratio and higher expected returns. Finally note that when preferences are constant, expected returns and price-dividend ratios are the same across sectors and, thus, there is no value premium in this case.

\subsection{Market volatility}

Figure 8.7 shows the volatility of the stock market for the different parametrization considered. Conformist investors find it very difficult to imitate the consumption portfolio of other agents when the market is dominated by one of the two assets. As a result, when the majority of investors are conformist, the stock market volatility increases when the popularity ratio is 0 or 1 and declines otherwise. Vice-versa, anti-conformist investors find it very difficult to differentiate themselves from other agents when the two goods have similar popularity. Therefore market volatility reaches its maximum for intermediate level of the popularity ratio and declines otherwise. Returns volatility equals the volatility of the numeraire at the extremes of the popularity ratio. Indeed, when $s_{t}$ reaches its 
boundaries ( 0 or 1$)$ preferences become constant and the numeraire fluctuation is the only risk priced by log investors (see Proposition 3 and the discussion below) and therefore the return volatility equals the volatility of the numeraire good. Finally note that with constant log-linear preferences the stock return volatility would be constant and always equal to the volatility of the numeraire good.

To build some further intuition on the relationship between preference evolution and stock market volatility one can think of asset pricing models with habit formation in the spirit of Campbell and Cochrane (1999). In those models return volatility is typically high in bad states, that is states where consumption approaches the inventors' reference level, because in those states discount rates are more sensitive to macroeconomic shocks. The popularity ratio in my model plays a role similar to that played by the reference level of consumption in models of habit formation. However states where consumption approaches the popularity ratio are not necessarily bad states but it depends on whether investors are conformist or anti-conformist. Conformist investors like states where their consumption is close to the average consumption in the economy and therefore those states are perceived as less risky and are associated with low return volatility. Differently anti-conformist investors prefer states where their consumption differ from the average consumption in the economy. Therefore, those states are perceived as less risky and are associated with lower stock market volatility.

In summary, preference evolution creates an endogenous link between the popularity of traded goods and the volatility of stock returns that makes return volatility stochastic and time-varying in a way that depends on the distribution of fashion sensitivity across investors. This differs from models with constant log-linear preference where the stock market volatility is constant and always equal to the volatility of the numeraire good, $\phi_{1}$.

\subsection{Sectoral wealth shares}

Standard general equilibrium asset pricing models predict that investors hold more wealth in sectors with the more convenient risk/return trade-off, that is, sectors with the higher mean or lower volatility of asset returns. In contrast to the theory, Bansal et al. 
(2005) find no relation between sectoral wealth and asset returns. More surprisingly, investors often hold more wealth in sectors with the worst risk/return trade-off. They refer to this evidence as the equity capital puzzle.

The risk/return trade-off of sector $i$ can be summarized by the traditional myopic stock allocation $\theta_{i, t}=\frac{\mu_{i, t}-r_{t}}{\sigma_{i, t}^{2}}$. In Figure $8.8 \mathrm{I}$ plot the difference in the risk-return tradeoff (i.e., $\left.\theta_{1, t}-\theta_{2, t}\right)$ and the wealth share ${ }^{7}$ of sector 1 (i.e., $\left.\frac{S_{1, t}}{S_{M, t}}\right)$. First we observe that the wealth share of sector 1 is increasing in the popularity ratio $s_{t}$ when the majority of investors are conformist and decreasing in the popularity ratio when the majority of investors are anti-conformist. Moreover, anti-conformist investors hold more wealth in sectors producing out-of fashion goods while conformist investors hold more wealth in sectors producing popular goods and this happens irrespective of the risk-return tradeoff. For instance, when good 1 is out-of fashion (i.e., for low values of the popularity ratio) anti-conformist investors hold more wealth in the sector producing out-of-fashion goods even if the risk/return trade-off of the other sector is more favorable. Similarly, conformist investors prefer to invest more in sectors producing fashionable goods even when the risk risk/return trade-off of out-of fashion sectors is more favorable. This means that the trading behavior of conformist and anti-conformist investors is mainly driven by fashions in the consumption market rather than by the risk/return trade-off of financial assets. This result helps to explain the equity capital puzzle of Bansal et al. (2005).

The dynamics of the wealth shares can also help us to understand other puzzling empirical findings concerning investors' trading behaviour. Recently, Barber and Odean (2000) and Barber et al. (2009) find that the average portfolio performance of individual investors under-perform a range of benchmarks. The natural question is then the following: why do investors trade in a way that hurt their performance? My model offers a simple answer to this question. Investors prefer buying stocks of the socially preferred sector irrespective of any performance measures, like the Sharpe ratio and, as a result, they may end up with a portfolio of socially desirable but poorly performing stocks.

\footnotetext{
${ }^{7}$ Given that financial wealth and portfolios are the same across all investors, wealth share and portfolios coincide.
} 


\subsection{Empirical implications}

The results of the previous sections show that a model with endogenous preferences evolution can explain several regularities of financial markets and investor behavior. In order to provide empirical support for the economic mechanism proposed in this paper one needs to find an empirical measure for the popularity of consumption goods. One possibility is to measure the popularity of consumption goods by using search frequency in Google. Da et al. (2011b) show that an increase in the search frequencies of a firm's most popular product predicts higher firm's revenue and stock returns. This is consistent with a model where the individual preferences are driven by the popularity of commercial products and agents are conformist. Moreover, Da et al. (2011a) have proposed to measure investors' attention for stocks by using the search frequency of a firm's ticker. They find that an increase in the search frequency of a given asset predicts a price increase in the short-run and a price decrease in the long-run. Da et al. (2011a,b) interpret search frequencies as a measure of investors' attention. However, to the extent that search frequencies can also be interpreted as popularity measures of commercial products, the empirical findings of Da et al. (2011a,b) can be interpreted as suggesting a link between the popularity of consumption goods and asset prices which supports the mechanism of preference evolution proposed in this paper.

Another piece of evidence in favour of a link between preference evolution and portfolio choice is provided by Hwang (2011). He shows that the US demand for securities from a given country is positively related with the country popularity among American investors. This further evidence confirms that the popularity of consumption goods is a plausible driver of investors' portfolios and should therefore be incorporated into models of asset prices and portfolio choice.

\section{Conclusion}

This paper examines a version of the Lucas economy in which investors' preferences evolve over time as a function of the perceived popularity of consumption goods. The 
interaction of preference evolution and traditional market-based forces of pure-exchange economies generates properties of stock returns consistent with the empirical literature of asset pricing such as time-varying volatility, value and growth effect. Moreover, endogenous preference evolution can help explain the observed under-diversification and local biases of investors' portfolios. These results are obtained in a simple endowment economy with log utility functions and i.i.d. normal sectoral cash-flows. Therefore they are not meant to quantitatively match the empirical asset pricing literature. Instead, my main goal is to show that time variation in preferences is not only a plausible component of the investors' decision process (as already pointed out in the economic literature), but also helps to reproduce features of investor behavior and stock returns that would otherwise be difficult to obtain in models characterized by the simple ingredients listed above.

I conclude this section with remarks on possible extensions of the current setup. In this paper, I explicitly assume that preferences evolve on a global basis in the sense that their evolution depends on the average consumption share of all agents in the economy. However, it would be interesting to study an economy where the agents' preferences are influenced by the entire distribution of consumption share, including the higher-order moments. This would capture the idea that the preferences of an agent are influenced more by the agents with whom he or she has direct contact than by agents with more distant contact. A model of local preference evolution can also be obtained by assuming that agents are divided into social groups and that preference evolution depends on the average consumption share of agents in a given social groups. These challenges are left for future research. 


\section{References}

Bansal, R., E. Bansal, and A. Yaron. 2005. Equity capital: a puzzle? Working paper .

Barber, B., Y. Lee, Y. Liuu, and T. Odean. 2009. Just how much do investors lose from trade? The Review of Financial Studies 22:151-186.

Barber, B., and T. Odean. 2000. Trading is hazardous to your wealth: the common stock performance of individual investors. Journal of Finance 55:773-806.

Bell, A. M. . 2002. Local interdependent preferences in a general equilibrium environment. Journal of Economic Behavior and Organization 47:303-333.

Branger, N., C. Schlag, and L. Wu. 2011. Pricing two heterogeneous trees. Journal of Financial and Quantitative Analysis 46:1437-1426.

Brennan, M., and H. Cao. 1997. International Portfolio Investment Flows. Journal of Finance 52:1851-1880.

Campbell, J., and J. Cochrane. 1999. By force of habit: a consumption based explanation of aggregate stock market behavior. Journal of Political Economy 107:205-251.

Cass, D., and A. Pavlova. 2004. On trees and logs. Journal of Economic theory 116:41-83.

Chabakauri, G. 2013. Dynamic equilibrium with two stocks, heterogeneous investors, and portfolio constraints. The Review of Financial Studies 26:3104-3141.

Chan, Y. L., and L. . Kogan. 2002. Catching up with the Joneses: heterogeneous preferences and the dynamics of asset prices. Journal of Political Economy 110:1255-1285.

Chen, H. J. 2014. Do cash flows of growth stocks really grow faster? Working Paper .

Cochrane, J. H., F. A. Longstaff, and P. Santa-Clara. 2008. Two trees. The Review of Financial Studies 21:347-385.

Croce, M. M., M. Lettau, and S. C. Ludvigson. 2014. Investor information, long-run risk and the term strucutre of equity. Forthcoming, The Review of Financial Studies . 
Da, Z., J. Engelberg, and P. Gao. 2011a. In search of attention. Journal of Finance 5:1461-1500.

Da, Z., J. Engelberg, and P. Gao. 2011b. In search of fundamentals. Working Paper .

Duesenberry, J. S. 1949. Income, saving, and the theory of consumer behavior. Cambridge, MA: Harward University Press .

Fama, E. F., and K. . R. French. 1992. The cross section of stock returns. Journal of Finance 47:427-465.

Feng, L., and M. S. Seasholes. 2004. Correlated trading and location. The Journal of Finance 59:2017-2044.

French, K. R., and J. M. Poterba. 1991. Investor diversification and international equity markets. American Economic Review 81:222-226.

Garcia, D., and G. Strobl. 2011. Relative wealth concerns and complementaries in information acquisition. Review of Financial Studies 24:169-207.

García-Peñalosa, C., and S. J. Turnovsky. 2008. Consumption externalities: a representative consumer model when agents are heterogeneous. Economic Theory 37:439-467.

Gehrig, T. 1993. An informational based explanation of the domestic bias in international equity investments. Scandinavian Journal of Economics 95:97-109.

Gollier, C. 2004. Misery loves company: equilibrium portfolios with consumption externalities. International Economic Review 45:1169-1191.

Grinblatt, M., and M. Keloharju. 2001. How distance, language, and culture influence stockholdings and trades. The Journal of Finance 56:1053-1073.

Hatchondo, J. C. 2008. Asymmetric information and the lack of portfolio diversification. International Economic Review 49:1297-1330.

Hong, H., J. D. Kubik, and J. C. Stein. 2004. Social interactions and stock market participation. The Journal of Finance 59:137-163. 
Hong, H., J. D. Kubik, and J. C. Stein. 2005. Thy neighbour's portfolio: word-of-mouth effects in the holdings and trades of money managers. The Journal of Finance 20:13271357.

Huberman, G. 2001. Familiarity breeds investment. The Review of Financial Studies 14:659-680.

Hwang, B. H. 2011. Country-specific sentiment and security prices. Journal of Financial Economics 100:382-401.

Ivković, Z., and S. Weisbenner. 2005. Local does as local is: information conternt and the geography of invidual investors' common stock investments. The Journal of Finance 60:267-306.

Ivković, Z., and S. Weisbenner. 2007. Information diffusion effects in indiviaula investors' common stock purchases: covet thy neghbours' investment choices. Review of Financial Studies 20:1327-1357.

Karatzas, I., J. P. Lehoczky, and E. Shreve. 1987. Optimal portfolio and consumption decisions for a small investor on a finite horizon. SIAM Journal on Control and Optimization 25:1577-1586.

Leroy, S., and R. Porter. 1981. The present value relation: tests based on variance bouds. Econometrica 49:555-577.

Lettau, M., and J. Wachter. 2007. Why is long-horizon equity less risky? a duration-based explanation of the value premium. Journal of Finance 62:55-92.

Lintner, J. 1965. Security prices, risk and maximal gains from diversification. Journal of Finance 20:587-615.

Lucas, R. E. 1978. Asset prices in an exchange economy. Econometrica 46:1429-1445.

Martin, I. 2013. The Lucas Orchard. Econometrica 81:55-111. 
Pavlova, A., and R. Rigobon. 2007. Asset prices and exchange rates. The Review of Financial Studies 20:1139-1180.

Pollak, R. A. 1979. Interdependent Preferences. The American Economic Review 66:309320.

Seasholes, M. S., and N. Zhu. 2010. Individual investors and local bias. The Journal of Finance 65:1987-2010.

Sharpe, W. 1964. Capital asset prices: a theory of market equilibrium under conditions of risk. Journal of Finance 19:425-444.

Veblen, T. 1899. The theory of the leisure class. New York: The Modern Library . 


\section{Appendix A: Proofs}

\subsection{Proof of Propositions}

Proof of Lemma 1. Consider first conformist investors $(k>0)$. Since $s_{t} \in[0,1]$ the minimum value of $\alpha_{t}$ is attained at $s_{t}=0$ that is

$$
\alpha_{t}=\bar{\alpha}-k \bar{s}
$$

and the maximum value is obtained at $s_{t}=1$, that is

$$
\alpha_{t}=\bar{\alpha}+k(1-\bar{s})
$$

Then, $\alpha_{t} \in[0,1]$ if

$$
\begin{aligned}
\bar{\alpha}-k \bar{s} & \geq 0 \\
\bar{\alpha}+k(1-\bar{s}) & \leq 1
\end{aligned}
$$

The two inequalities have to hold for any $k$. Since $k, \bar{s}$ and $(1-\bar{s})$ are positive constants, it is sufficient to require that the previous inequalities hold for $\bar{k}$

$$
\begin{aligned}
\bar{\alpha}-\bar{k} \bar{s} & \geq 0 \\
\bar{\alpha}+\bar{k}(1-\bar{s}) & \leq 1 .
\end{aligned}
$$

For anti-conformist investors $k<0$ and therefore we require

$$
\begin{aligned}
\bar{\alpha}-k \bar{s} & \leq 1 \\
\bar{\alpha}+k(1-\bar{s}) & \geq 0
\end{aligned}
$$

Since $k<0$, to have $\alpha_{t} \in[0,1]$ for any $k$ it is sufficient to require that the previous inequalities hold for $\underline{k}$.

Proof of Proposition 1. Plugging optimal consumption choices 9 and 10 into the resource constraints of problem 8 we obtain

$$
\begin{aligned}
& \int_{\underline{k}}^{\bar{k}} e^{-\rho t} \frac{0.5+k\left(s_{t}-0.5\right)}{\Delta k} d k \\
& \quad=e^{-\rho t} \frac{0.5}{\Delta k}\left(\Delta k+\Delta k^{2}\left(s_{t}-0.5\right)\right)=\lambda_{t} \delta_{1, t}
\end{aligned}
$$


and

$$
\begin{aligned}
\int_{\underline{k}}^{\bar{k}} & e^{-\rho t} \frac{0.5-k\left(s_{t}-0.5\right)}{\Delta k} d k \\
& =e^{-\rho t} \frac{0.5}{\Delta k}\left(\Delta k-\Delta k^{2}\left(s_{t}-0.5\right)\right)=p_{2, t} \lambda_{t} \delta_{2, t} .
\end{aligned}
$$

Solving for $\lambda_{t}$ and $p_{t}$ gives

$$
\begin{aligned}
& \lambda_{t}=e^{-\rho t} \frac{\left(\Delta k+\Delta k^{2}\left(s_{t}-0.5\right)\right)}{2 \Delta k \delta_{1, t}} \\
& p_{2, t}\left(s_{t}, x_{t}\right)=\frac{\Delta k-\Delta k^{2}\left(s_{t}-0.5\right)}{\Delta k+\Delta k^{2}\left(s_{t}-0.5\right)} x_{t}
\end{aligned}
$$

Proof of Corollary 2. The results of the Corollary follows by substituting the state price density and relative price given in Proposition 1 into optimal consumption choices 9 and 10.

Proof of Proposition 2. Using again the optimal consumption 9 and 10 we have

$$
\frac{c_{1 t}}{c_{1 t}+c_{2 t}}=\frac{p_{2, t}\left(0.5+k\left(s_{t}-0.5\right)\right)}{0.5\left(1+p_{2, t}\right)+k\left(p_{2, t}-1\right)\left(s_{t}-0.5\right)}
$$

thus,

$$
\begin{aligned}
s_{t} & =\frac{1}{\Delta k} \int_{\underline{k}}^{\bar{k}} \frac{p_{2, t}\left(0.5+k\left(s_{t}-0.5\right)\right)}{0.5\left(1+p_{2, t}\right)+k\left(p_{2, t}-1\right)\left(s_{t}-0.5\right)} d k \\
& =\frac{1}{\Delta k}\left[\int_{0}^{\bar{k}} \frac{p_{2, t}\left(0.5+k\left(s_{t}-0.5\right)\right)}{0.5\left(1+p_{2, t}\right)+k\left(p_{2, t}-1\right)\left(s_{t}-0.5\right)} d k\right. \\
& \left.+\int_{\underline{k}}^{0} \frac{p_{2, t}\left(0.5+k\left(s_{t}-0.5\right)\right)}{0.5\left(1+p_{2, t}\right)+k\left(p_{2, t}-1\right)\left(s_{t}-0.5\right)} d k\right] \\
& =\frac{1}{\Delta k}\left[f\left(s_{t}, x_{t}, \bar{k}\right)-f\left(s_{t}, x_{t}, \underline{k}\right)\right]
\end{aligned}
$$

where

$$
\begin{aligned}
f\left(s_{t}, x_{t}, y\right) & =\int_{0}^{y} \frac{p_{2, t}\left(0.5+k\left(s_{t}-0.5\right)\right)}{0.5\left(1+p_{2, t}\right)+k\left(p_{2, t}-1\right)\left(s_{t}-0.5\right)} d k \\
& =\frac{p_{2, t}}{p_{2, t}-1}\left[y+\frac{\log \left(\frac{0.5\left(1+p_{2, t}\right)}{0.5\left(1+p_{2, t}\right)+y\left(p_{2, t}-1\right)\left(s_{t}-0.5\right)}\right)}{\left(p_{2, t}-1\right)\left(s_{t}-0.5\right)}\right] .
\end{aligned}
$$

Therefore, the proof of the Proposition consists in demonstrating that the fixed-point 
problem

$$
F\left(s_{t}, x_{t}\right)=s_{t}-\frac{1}{\Delta k}\left[f\left(s_{t}, x_{t}, \bar{k}\right)-f\left(s_{t}, x_{t}, \underline{k}\right)\right]=0
$$

admits a unique solution $s_{t}^{*}$; To complete the proof of the Proposition I need to establish the following properties of the function $F\left(s_{t}, x_{t}\right)$

Property 1: Existence of $s_{t}^{*}$.

Proof: $\frac{1}{\Delta k} \int_{\underline{k}}^{\bar{k}} \frac{p_{2, t}\left(0.5+k\left(s_{t}-0.5\right)\right)}{0.5\left(1+p_{2, t}\right)+k\left(p_{2, t}-1\right)\left(s_{t}-0.5\right)} d k$ is a continuous function of $s_{t}$ mapping [0,1] into itself. As a result, the Brouwer's fixed point theorem guarantees the existence of at least one $s_{t}^{*}$ such that $F\left(s_{t}^{*}, x_{t}\right)=0$.

Property 2: Monotonicity of $s_{t}^{*}$ with respect to $x$.

Proof: The function $c_{1 t}\left(k, s_{t}\right) /\left(c_{1 t}\left(k, s_{t}\right)+c_{2 t}\left(k, s_{t}\right)\right)$, is strictly increasing in $x_{t}$ for any $k$ as can be verified by direct differentiation. Therefore the arithmetic average $\frac{1}{\Delta k} \int_{\underline{k}}^{\bar{k}} c_{1 t}\left(k, s_{t}\right) /\left(c_{1 t}\left(k, s_{t}\right)+c_{2 t}\left(k, s_{t}\right)\right) d k$ must also be strictly increasing in $x_{t}$. Thus, $s_{t}^{*}$ is monotonic increasing in $x_{t}$.

Property 3: Monotonicity of $F\left(s_{t}, x_{t}\right)$ with respect to $x$.

Proof: Differentiating $F$ with respect to $x$

$$
\frac{\partial F\left(s_{t}, x_{t}\right)}{\partial x_{t}}=-\frac{1}{\Delta k} \frac{\left(\Delta k-\Delta k^{2}\left(s_{t}-0.5\right)\right)}{\left(\Delta k+\Delta k^{2}\left(s_{t}-0.5\right)\right)} \int_{\underline{k}}^{\bar{k}}\left(\frac{\alpha_{t}\left(1-\alpha_{t}\right)}{\left(p_{2, t} \alpha_{t}+1-\alpha_{t}\right)^{2}}\right) d k<0
$$

From which we conclude that $F$ is monotonically decreasing in $x$.

Property 4: $F$ changes sign on its support.

Proof: The limiting values of $F$ are given by

$$
\begin{aligned}
& \lim _{x \rightarrow 0} F\left(0, x_{t}\right)=0 \\
& \lim _{x \rightarrow \infty} F\left(1, x_{t}\right)=0
\end{aligned}
$$

which, in conjunction with Property 3 , imply that $F\left(0, x_{t}\right) \leq 0 \forall x_{t}$ and $F\left(1, x_{t}\right) \geq 0 \forall x_{t}$.

Properties $1-4$ are illustrated in Figure 7.1 below. Armed with these results we can proceed to prove uniqueness of $s_{t}^{*}$. Properties 1 and 4 together imply that $F\left(s_{t}, x_{t}\right)$ has to be either monotonically increasing or non monotone with the additional constraints that $F\left(0, x_{t}\right) \leq 0 \forall x_{t}$ and $F\left(1, x_{t}\right) \geq 0 \forall x_{t}$. If $F\left(s_{t}, x_{t}\right)$ is monotonically increasing, Property 4 implies that $s_{t}^{*}$ is unique and the proof is concluded. Assume now that $F\left(s_{t}, x_{t}\right)$ is not monotone. Then, the fixed point problem $F\left(s_{t}, x_{t}\right)=0$ admits multiple solutions and let $s_{x}^{*}=\left[s_{x, 1}^{*}, s_{x, 2}^{*}, \ldots, s_{x, N}^{*}\right]$ be a vector containing $N$ solutions of $F\left(s_{t}, x_{t}\right)=0$ for the same value of the relative supply $x$. Take now two different values of $x$, say $x_{1}$ and $x_{2}$ such that $x_{1}<x_{2}$. By property 3 we must have $F\left(s_{t}, x_{2}\right)<F\left(s_{t}, x_{1}\right)$ which implies that there exist $s_{x_{1}, i}^{*}$ and $s_{x_{2}, j}^{*}$ such that $s_{x_{1}, i}^{*}>s_{x_{2}, j}^{*}$ for some $i, j \leq N$ which violates Property 2 . Therefore, we conclude that $s_{t}^{*}$ must be unique. 
Finally, uniqueness of $s_{t}^{*}$ and Property 4 together imply that $\lim _{x \rightarrow 0} s_{t}^{*}=0$ and $\lim _{x \rightarrow \infty} s_{t}^{*}=1$.

Proof of Corollary 3. The market clearing conditions in an economy with no heterogeneity are given by

$$
\begin{aligned}
& c_{1 t}=\frac{e^{-\rho t}\left(0.5+k\left(s_{t}-0.5\right)\right)}{\lambda_{t}}=\delta_{1, t} \\
& c_{2 t}=\frac{e^{-\rho t}\left(0.5-k\left(s_{t}-0.5\right)\right)}{\lambda_{t} p_{2, t}}=\delta_{2, t}
\end{aligned}
$$

which immediately imply that $s_{t}=c_{1 t} /\left(c_{1 t}+c_{1 t}\right)=\delta_{1, t} /\left(\delta_{1, t}+\delta_{2, t}\right)$. Solving the market clearing equations for $\lambda_{t}$ and $p_{t}$ gives the desired result from the state-price density and the relative price of the two goods.

Proof of Corollary 4. The results follow from Corollary 3 by setting $k=0$.

Proof of Proposition 3. The risk free rate and the price of risk process follows by applying Itô's lemma to the state price density $\lambda_{t}$ given in Proposition 1 and comparing the resulting coefficients with Eq. (13).

Proof of Proposition 4. Using $\lambda_{t}$ and $p_{2, t}$ from Proposition 1 we obtain

$$
\begin{aligned}
S_{1, t} & =\mathbb{E}_{t}\left[\int_{t}^{\infty} \frac{\lambda_{s} \delta_{1, s}}{\lambda_{t}} d s\right] \\
& =\delta_{1, t} \frac{\frac{\Delta k-0.5 \Delta k^{2}}{\rho}+\Delta k^{2} \int_{t}^{\infty} e^{-\rho(s-t)} \mathbb{E}_{t}\left[s_{s}\right] d s}{\Delta k+\Delta k^{2}\left(s_{t}-0.5\right)}
\end{aligned}
$$

where the second equality follows by computing integrals over time. Similarly for asset 2

$$
\begin{aligned}
S_{2, t} & =\mathbb{E}_{t}\left[\int_{t}^{\infty} \frac{\lambda_{s} p_{2, s} \delta_{2, s}}{\lambda_{t}} d s\right] \\
& =\delta_{2, t} \frac{\frac{\Delta k+0.5 \Delta k^{2}}{\rho}-\Delta k^{2} \int_{t}^{\infty} e^{-\rho(s-t)} \mathbb{E}_{t}\left[s_{s}\right] d s}{\Delta k+\Delta k^{2}\left(s_{t}-0.5\right)} .
\end{aligned}
$$




\subsection{A decentralized economy with preference evolution}

Consider an economy with a continuum of agents who differ form each other with respect to their fashion sensitivity $k$. Given $k$, each agent solves

$$
\begin{aligned}
& \max _{c_{1, t}(k), c_{2, t}(k)} \mathbb{E}\left[\int_{0}^{\infty} e^{-\rho t}\left(\alpha_{t}(k) \log c_{1, t}+\left(1-\alpha_{t}(k)\right) \log c_{2, t}\right) d t\right] \\
& \text { s.t. } \quad \mathbb{E}\left[\int_{0}^{\infty}\left(\lambda_{t} c_{1, t}+\lambda_{t} p_{2, t} c_{2, t}\right) d t\right]=w_{0}(k)
\end{aligned}
$$

where $w_{0}(k)$ is the agent specific initial wealth. Taking the FOC of the previous maximization problem we obtain

$$
\begin{aligned}
& e^{-\rho t} \frac{\alpha_{t}(k)}{c_{1, t}}=y \lambda_{t} \Rightarrow c_{1, t}^{*}=e^{-\rho t} \frac{\alpha_{t}(k)}{y \lambda_{t}} \\
& e^{-\rho t} \frac{1-\alpha_{t}(k)}{c_{2, t}}=y \lambda_{t} p_{2, t} \Rightarrow c_{2, t}^{*}=e^{-\rho t} \frac{1-\alpha_{t}(k)}{y \lambda_{t} p_{2, t}}
\end{aligned}
$$

where $y$ is the Lagrange multiplier attached to the budget constraint and satisfies

$$
w_{0}(k)=\mathbb{E}\left[\int_{0}^{\infty}\left(\lambda_{t} c_{1, t}^{*}+\lambda_{t} p_{2, t} c_{2, t}^{*}\right) d t\right]=\int_{0}^{\infty} \frac{e^{-\rho t}}{y} d t
$$

where the last equality uses the optimal consumption from the FOC. Clearly, if $w_{0}(k)=$ $\bar{w} \quad \forall k$ then the Lagrange multiplier $y$ is the same across agents. Therefore if we set $y=\frac{1}{g}$ (where $g$ is the social weight) the optimal demand of consumption and assets are the same as those obtained by solving the social planner problem. This shows that a decentralized economy where investors i) are equipped with log utility and time-varying preferences and ii) have the same initial wealth is equivalent to a centrally-planned economy where a social planner maximizes a weighted average of individual utility functions and assigns the same weight to all agents. 


\section{Appendix B: Numerical Method}

In order to solve for the equilibrium I have to compute numerically the following quantities:

$$
s^{*}\left(x_{t}\right), \quad \frac{\partial s^{*}\left(x_{t}\right)}{\partial x_{t}}, \quad \frac{\partial^{2} s^{*}\left(x_{t}\right)}{\partial x_{t}^{2}}, \quad \mathbb{E}_{t}\left[s^{*}\left(x_{s}\right)\right] \quad \text { for } \quad s \geq t
$$

I proceed as follows. First, I construct the function $s^{*}(x)$ by solving numerically the fixed-point problem 12 on a fine grid of the relative endowment $x$ with 5000 equally spaced points between .001 and 100. For $x \geq 100 s^{*}$ is approximately equal to 1 and almost constant. Then, first and second order derivative of $s^{*}$ are approximated using the finite-difference method. Notice now that

$$
d x=x \mu_{x} d t+x\left(\phi_{1} d B_{1}-\phi_{2} d B_{2}\right)
$$

where $\mu_{x}=\nu_{1}-\nu_{2}+\phi_{2}^{2}$. This implies that $\log \left(x_{s}\right)$ is a normal random variable with conditional mean $\left(\mu_{x}-.5\left(\phi_{1}^{2}+\phi_{2}^{2}\right)\right)(s-t)$ and variance $\left(\phi_{1}^{2}+\phi_{2}^{2}\right)(s-t)$, for any time $s \geq t$. Finally, I compute the expected value $\mathbb{E}_{t}\left[s^{*}\left(x_{s}\right)\right]$ using standard quadrature technique in conjunction with the distributional properties of $x$.
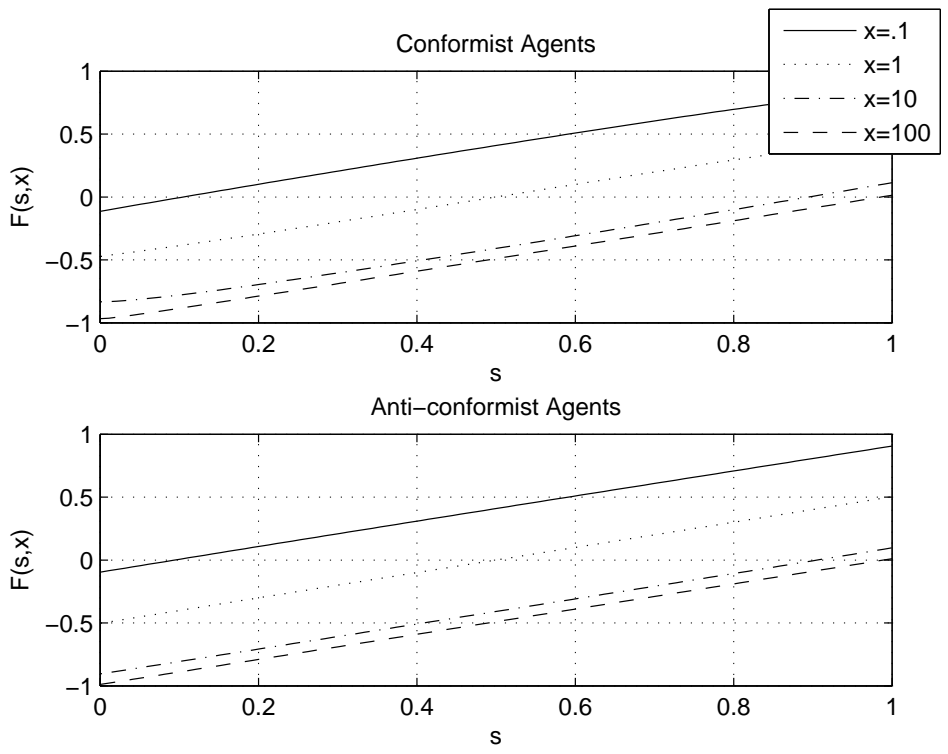

Figure 7.1: The fixed point equation $F(s, x)$ plotted as a function of $s$ for different values of the relative endowment $x$. Upper panel: the economy with a majority of conformist investors. Lower panel: the economy with a majority of anti-conformist investors. 


\section{Appendix C: Figures and Tables}

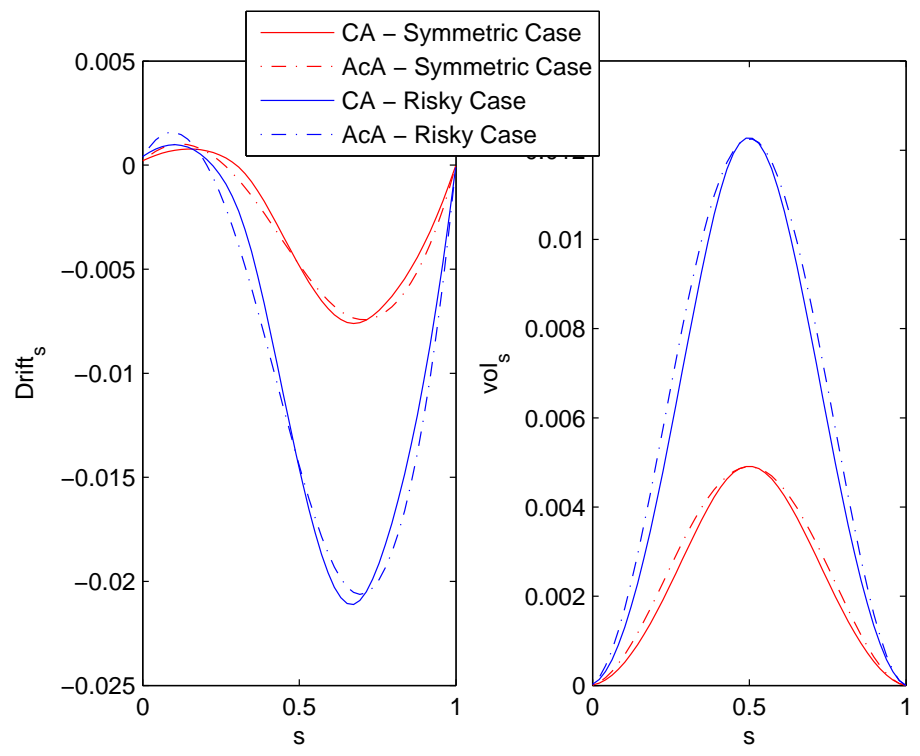

Figure 8.1: The drift rate (left panel) and the diffusion of the popularity ratio as a function of $s_{t}$. "CA" stays for Conformist Agents and refers to an economy where the majority of agents are conformist. "AcA" stays for Anti-conformist Agents and refers to an economy where the majority of agents are anti-conformist.

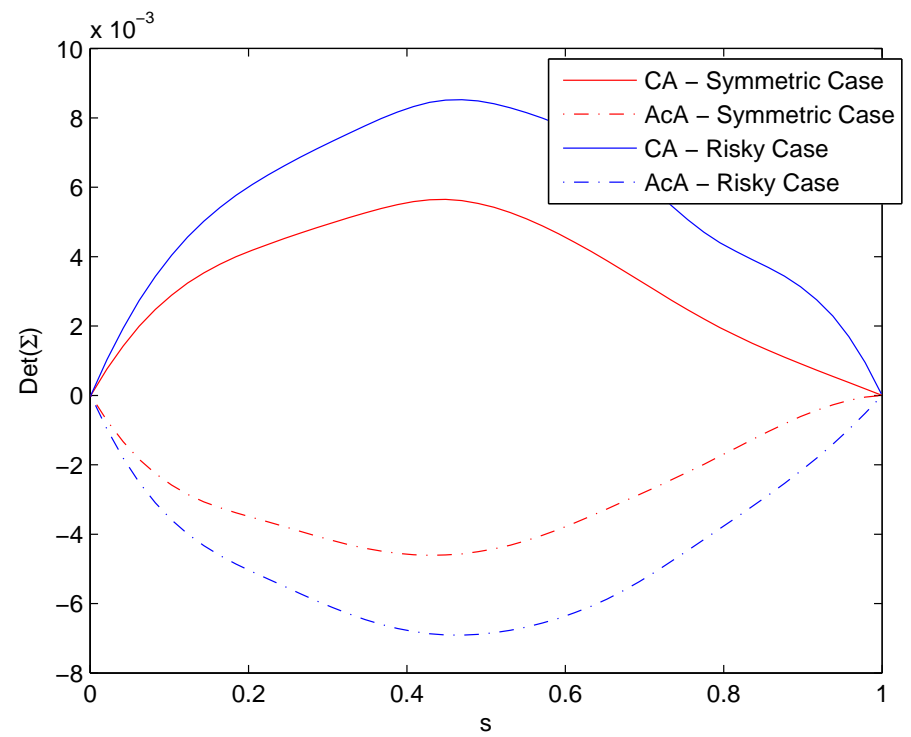

Figure 8.2: The determinant of the volatility matrix is plotted as a function of $s_{t}$. "CA" stays for Conformist Agents and refers to an economy where the majority of agents are conformist. "AcA" stays for Anti-conformist Agents and refers to an economy where the majority of agents are anti-conformist. 


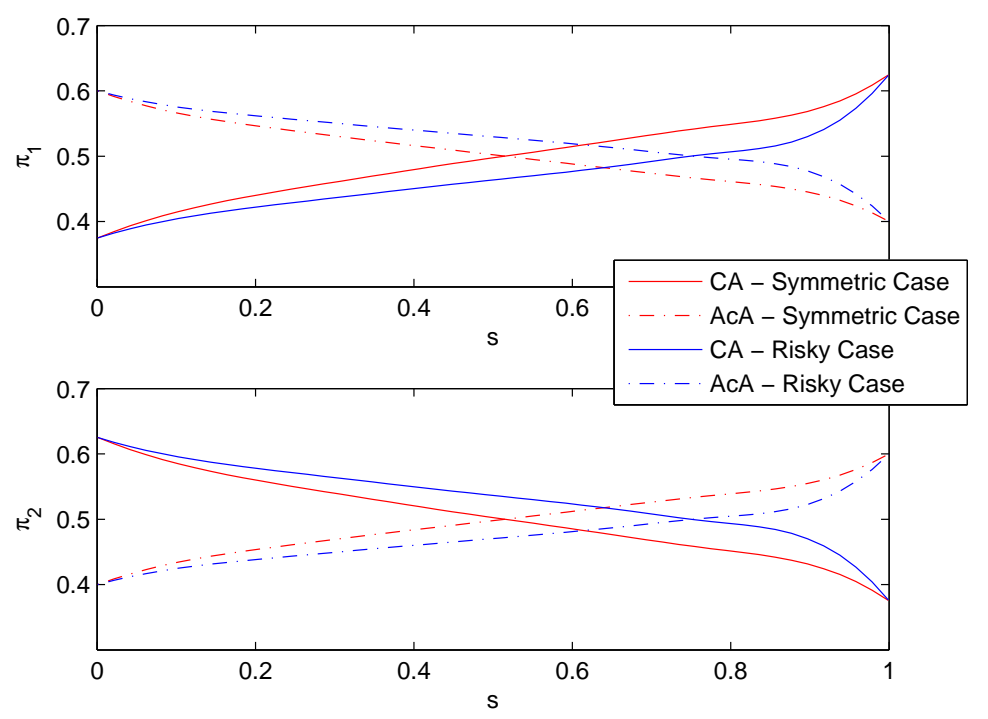

Figure 8.3: Optimal fraction of wealth invested in the 2 risky assets as a function of $s_{t}$. "CA" stays for Conformist Agents and refers to an economy where the majority of agents are conformist. "AcA" stays for Anti-conformist Agents and refers to an economy where the majority of agents are anti-conformist.
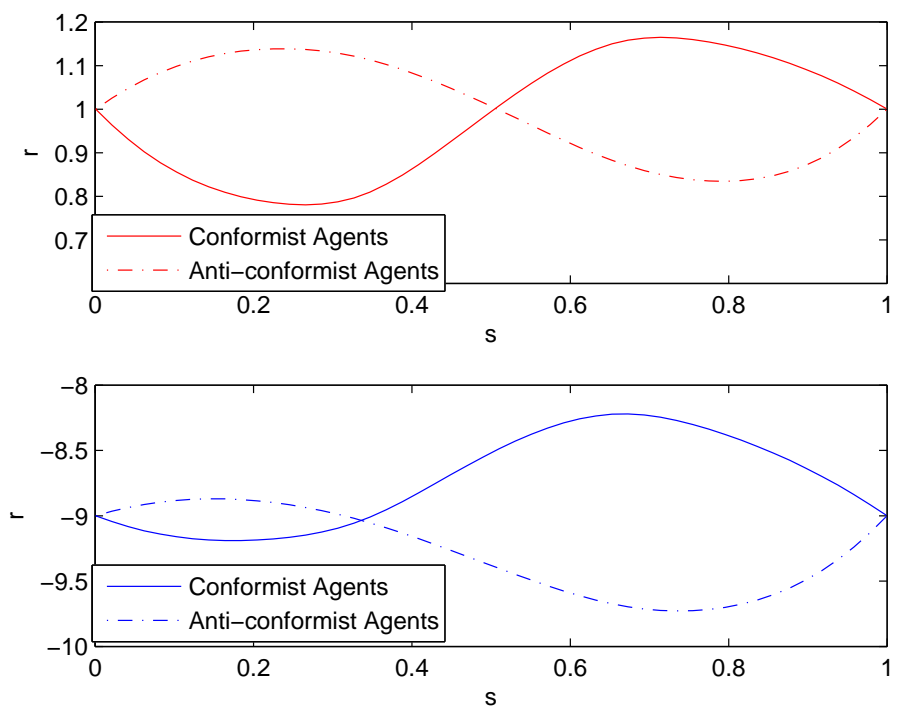

Figure 8.4: The instantaneous risk-free rate as a function of $s_{t}$. "CA" stays for Conformist Agents and refers to an economy where the majority of agents are conformist. "AcA" stays for Anti-conformist Agents and refers to an economy where the majority of agents are anti-conformist. 


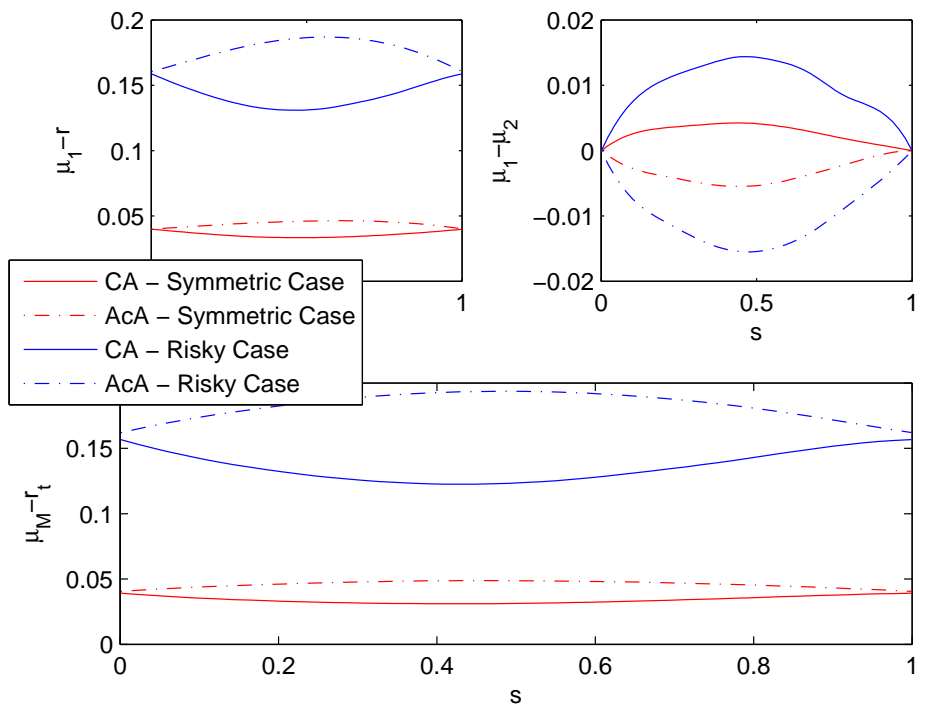

Figure 8.5: The excess return of asset 1 (upper left panel panel), the difference between the expected returns of the two assets (upper right) and the excess return of the market as a function of $s_{t}$. "CA" stays for Conformist Agents and refers to an economy where the majority of agents are conformist. "AcA" stays for Anti-conformist Agents and refers to an economy where the majority of agents are anti-conformist.

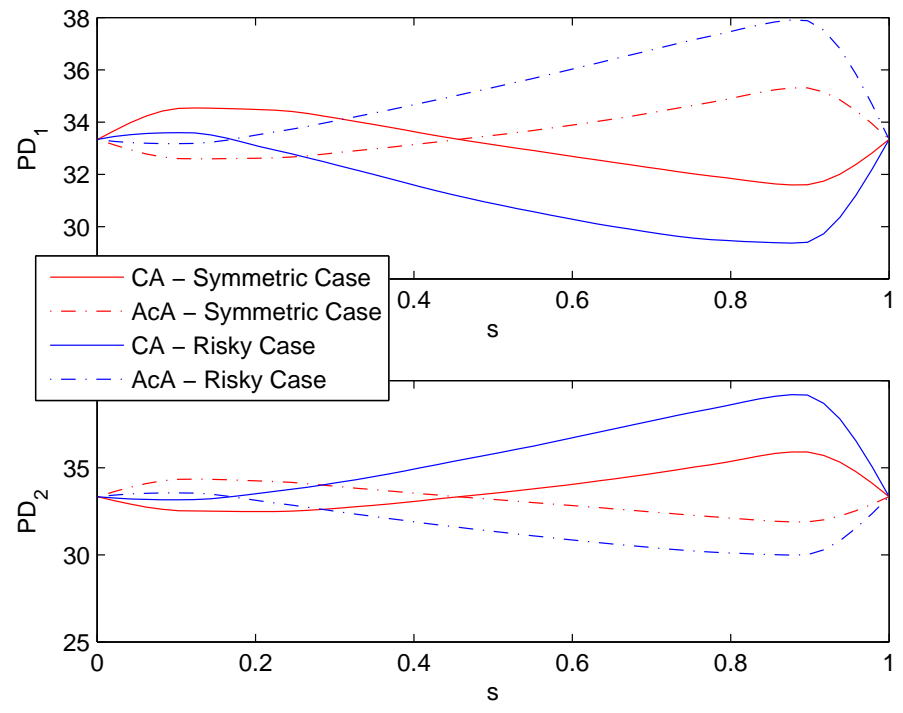

Figure 8.6: The price dividend ratios of asset 1 (upper panel) and asset 2 as a function of $s_{t}$. "CA" stays for Conformist Agents and refers to an economy where the majority of agents are conformist. "AcA" stays for Anti-conformist Agents and refers to an economy where the majority of agents are anti-conformist. 


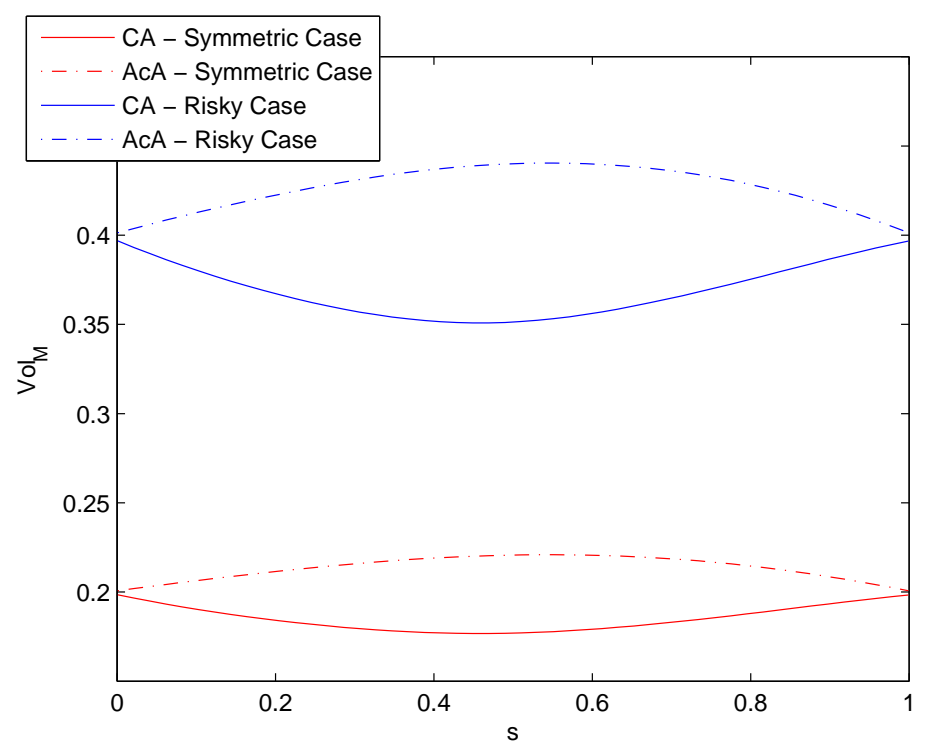

Figure 8.7: The volatility of the market as a function of $s_{t}$. "CA" stays for Conformist Agents and refers to an economy where the majority of agents are conformist. "AcA" stays for Anti-conformist Agents and refers to an economy where the majority of agents are anti-conformist.
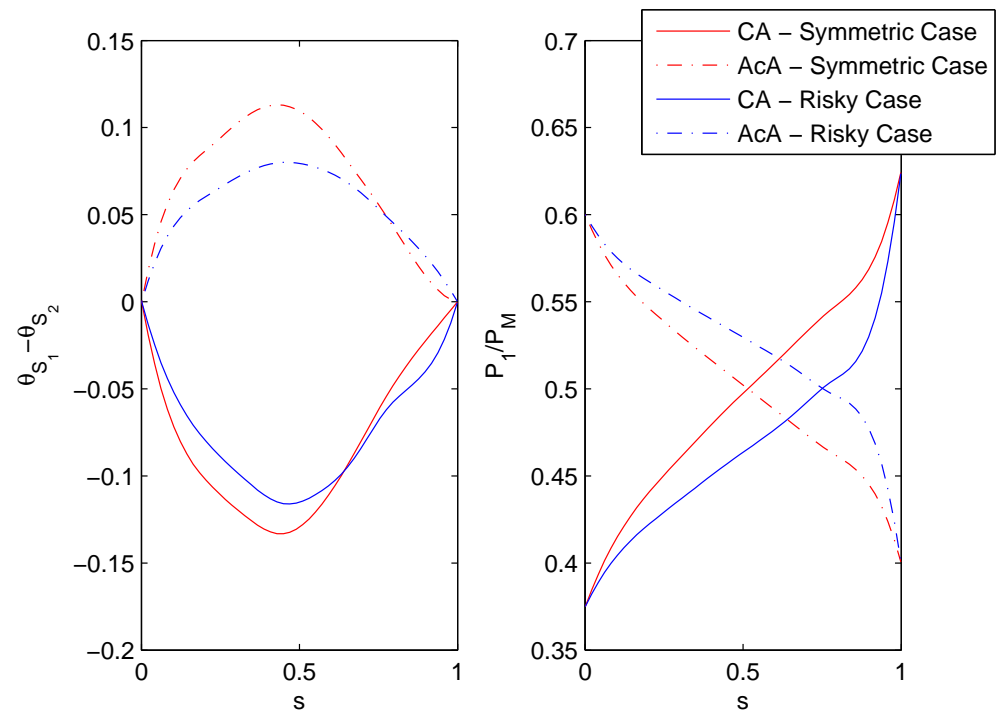

Figure 8.8: The difference between the myopic allocation in the two sectors (left panel) and the fraction of wealth allocated in sector 1 as a function of $s_{t}$. "CA" stays for Conformist Agents and refers to an economy where the majority of agents are conformist. "AcA" stays for Anti-conformist Agents and refers to an economy where the majority of agents are anti-conformist. 


\begin{tabular}{ccl}
\hline \hline Symbol & Value & Description \\
\hline $\bar{\alpha}$ & 0.5 & Initial preference for good 1 \\
$\bar{s}$ & 0.5 & Preference threshold \\
$\bar{k}$ & $0.1,1$ & Maximum sensitivity to fashion \\
$\underline{k}$ & -0.5 & Minimum sensitivity to fashion \\
$\rho$ & .03 & Subjective discount factor \\
$\nu_{1}$ & $0.02,0.04$ & Drift of dividend 1 \\
$\phi_{1}$ & $0.2,0.4$ & Volatility of dividend 1 \\
$\nu_{2}$ & 0.02 & Drift of dividend 2 \\
$\phi_{2}$ & 0.2 & Volatility dividend 2 \\
\hline \hline
\end{tabular}

Table 8.1: Model parameters: preferences, consumption and habit process. 


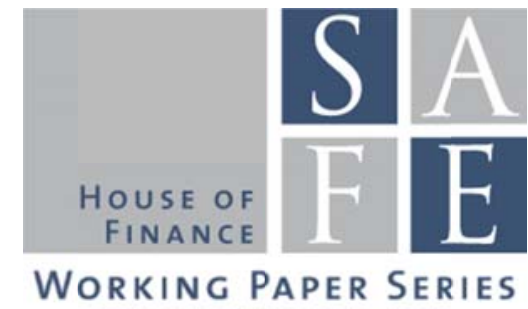

\section{Recent Issues}

No. 127 Helmut Elsinger, Philipp SchmidtDengler, Christine Zulehner

No. 126 Carsten Bienz, Karin S. Thorburn, Uwe Walz

No. 125 Tobias H. Tröger, Uwe Walz

No. 124 Adrian Buss, Bernard Dumas, Raman Uppal, Grigory Vilkov

No. 123 Marie Lalanne, Paul Seabright

No. 122 Douglas Cumming, Uwe Walz, Jochen Werth

No. 121 Elia Berdin, Matteo Sottocornola

No. 120 Matthias Heinz, Heiner Schumacher

No.119 Michael Brennan, Holger Kraft

No.118 Michael Donadelli, Antonio Paradiso, Max Riedel

No. 117 Marcel Bluhm

No. 116 Charles Gottlieb

No. 115 Andreas Fagereng, Charles Gottlieb, Luigi Guiso

No. 114 Nicole Branger, Christian Schlag, Lue $\mathrm{Wu}$

No. 11
Bettina Brüggemann, Jinhyuk Yoo
Competition in Treasury Auctions

Coinvestment and risk taking in private equity funds

Does Say on Pay Matter? Evidence from the German Natural Experiment

The Intended and Unintended Consequences of Financial-Market Regulations: A General Equilibrium Analysis

The Old Boy Network: The Impact of Professional Networks on Remuneration in Top Executive Jobs

The Dynamics of Entrepreneurial Careers in High-Tech Ventures: Experience, Education, and Exit

Insurance Activities and Systemic Risk

Signaling Cooperation

Leaning Against the Wind: Debt Financing in the Face of Adversity

A Quasi Real-Time Leading Indicator for the EU Industrial Production

Interbank Funding as Insurance Mechanism for (Persistent) Liquidity Shocks

On the Distributive Effects of Inflation

Asset Market Participation and Portfolio Choice over the Life-Cycle

'Nobody is Perfect': Asset Pricing and Long-Run Survival When Heterogeneous Investors Exhibit Different Kinds of Filtering Errors

Aggregate and Distributional Effects of Increasing Taxes on Top Income Earners 